\title{
An 11-year record of mass balance of Brewster Glacier, New Zealand, determined using a geostatistical approach
}

\author{
NICOLAS J. CULLEN, ${ }^{1}$ BRIAN ANDERSON, ${ }^{2}$ PASCAL SIRGUEY, ${ }^{3}$ \\ DOROTHEA STUMM, ${ }^{4}$ ANDREW MACKINTOSH, ${ }^{2,5}$ JONATHAN P. CONWAY, ${ }^{6}$ \\ HUW J. HORGAN, ${ }^{2,5}$ RUZICA DADIC, $^{2}$ SEAN J. FITZSIMONS, ${ }^{1}$ ANDREW LORREY ${ }^{7}$ \\ ${ }^{1}$ Department of Geography, University of Otago, PO Box 56, Dunedin, New Zealand \\ ${ }^{2}$ Antarctic Research Centre, Victoria University of Wellington, PO Box 600, Wellington, New Zealand \\ ${ }^{3}$ School of Surveying, University of Otago, Dunedin, New Zealand \\ ${ }^{4}$ International Centre for Integrated Mountain Development (ICIMOD), Kathmandu, Nepal \\ ${ }^{5}$ School of Geography, Environment and Earth Sciences, Victoria University of Wellington, PO Box 600, \\ Wellington, New Zealand \\ ${ }^{6}$ Bodeker Scientific, 42 Russell Street, Alexandra 9320, Central Otago, New Zealand \\ ${ }^{7}$ National Institute of Water and Atmospheric Research (NIWA), Auckland, New Zealand \\ Correspondence to: N. J. Cullen <nicolas.cullen@otago.ac.nz>
}

\begin{abstract}
Recognising the scarcity of glacier mass-balance data in the Southern Hemisphere, a massbalance measurement programme was started at Brewster Glacier in the Southern Alps of New Zealand in 2004. Evolution of the measurement regime over the 11 years of data recorded means there are differences in the spatial density of data obtained. To ensure the temporal integrity of the dataset a new geostatistical approach is developed to calculate mass balance. Spatial co-variance between elevation and snow depth allows a digital elevation model to be used in a co-kriging approach to develop a snow depth index $(S D I)$. By capturing the observed spatial variability in snow depth, the $S D I$ is a more reliable predictor than elevation and is used to adjust each year of measurements consistently despite variability in sampling spatial density. The SDI also resolves the spatial structure of summer balance better than elevation. Co-kriging is used again to spatially interpolate a derived mean summer balance index using $S D I$ as a co-variate, which yields a spatial predictor for summer balance. The average glacier-wide surface winter, summer and annual balances over the period 2005-15 are 2484, -2586 and $-102 \mathrm{~mm}$ w.e., respectively, with changes in summer balance explaining most of the variability in annual balance.
\end{abstract}

KEYWORDS: co-kriging, geostatistics, mass-balance reconstruction, mountain glaciers

\section{INTRODUCTION}

Monitoring surface mass balance of mountain glaciers is important as fluctuations in glacier mass over time have hydrological implications for water resource users and are used to infer changes in climate. An understanding of the contribution of glaciers and ice caps is also crucial in any assessment of global sea-level rise. A globally coordinated effort to obtain mass-balance measurements has enabled glacier-wide results from $>250$ glaciers to be documented (Zemp and others, 2015), with $>4000$ annual observations available spanning the past seven decades. However, the dataset is strongly biased towards the Northern Hemisphere and Europe. There are only 30 glaciers that have (almost) continuous measurements since 1976 (Zemp and others, 2009) and of these only one (Echaurren Norte, Andes) is located in the Southern Hemisphere, which is small (area $<0.40 \mathrm{~km}^{2}$ ) compared with the average size of the present 30 reference glaciers $\left(7.25 \mathrm{~km}^{2}\right.$ in 2003).

To address the issue of Southern Hemisphere glaciers being heavily under-represented in the global glacier monitoring network, a mass-balance programme on Brewster Glacier in the Southern Alps of New Zealand was initiated in 2004. The glaciers in the Southern Alps are unique by virtue of their location in the south-west Pacific, situated mid-way between Antarctica and the Equator. The Southern Alps are surrounded by vast areas of ocean and are strongly influenced by both subtropical and polar air masses, with the interaction of these contrasting air masses in the prevailing westerly airflow resulting in synoptic scale atmospheric circulation having a strong influence on glacier behaviour (Fitzharris and others, 1992, 1997; Clare and others, 2002; Gillett and Cullen, 2011). The massbalance programme on Brewster Glacier has provided a platform from which to assess glacier sensitivity to atmospheric forcing in the Southern Alps (Anderson and others, 2010; Gillett and Cullen, 2011; Conway and Cullen, 2013, 2016; Conway and others, 2015; Cullen and Conway, 2015).

Despite the importance of the glaciological record from Brewster Glacier, there have been numerous challenges associated with the task of producing a high-quality time series of mass balance. The challenges we have encountered on Brewster Glacier are no different to those reported by others contributing to the global monitoring network, with the main sources of random and systematic error linked to uncertainties associated with field measurements at point locations, spatial averaging of these observations over an entire glacier and the treatment of changes in area and elevation over time (e.g. Zemp and others, 2013). To ensure that 
the glaciological observations and a high quality massbalance record from Brewster Glacier are accessible to the glaciological community, the main purpose of this research is to describe a new geostatistical method developed to produce an 11-year record of mass balance. We anticipate our new approach will provide a methodological framework that allows historical 'debates' such as the relevancy of the number of point measurements taken each year in a massbalance programme (e.g. Fountain and Vecchia, 1999) to be scrutinised in a more systematic way.

We hypothesise that the spatial structure of winter and summer balance on Brewster Glacier for any individual mass-balance year contains sufficient similarity to other years to allow spatially distributed indices to be developed for each seasonal balance. To test this hypothesis we use a new geo-statistical approach to develop unique indices to calculate winter and summer mass balance. We also use the approach to create a predictor for annual balance, which allows us to revisit years when summer balance was not obtained. The glacier-wide estimates of winter, summer and annual mass balance are used to identify changes in equilibrium line altitude (ELA) and accumulation area ratio (AAR), as well as to resolve mass-balance gradients over the observational period. Finally, we assess the relationship between the mass-balance record and a longer record of ELA determined from the end-of-summer snowline (EOSS) programme (Chinn and others, 2012), which has been the benchmark for monitoring glaciers in the Southern Alps.

\section{SITE DESCRIPTION}

Brewster Glacier is a small, maritime glacier situated in the Southern Alps immediately west of the main divide $\left(44.08^{\circ} \mathrm{S}\right.$, $169.43^{\circ} \mathrm{E}$ ), with a surface area of $2.03 \mathrm{~km}^{2}$ (Fig. 1). The length of the glacier is $\sim 2.5 \mathrm{~km}$, with its elevation ranging between 1700 and $2400 \mathrm{~m}$ a.s.l. At higher altitudes (>2000 $\mathrm{m}$ a.s.l.), the glacier has a south-westerly aspect and a mean slope of $31^{\circ}$, while the lower, larger portion of the glacier $(77 \%$ of its total area) has a southerly aspect and is more gently sloping (mean slope of $10^{\circ}$ ). The upper and smaller part of the glacier situated below the summit of Mount Brewster contains a number of large ice cliffs. Brewster Glacier is one of 50 'index glaciers' in the Southern Alps that has been surveyed as part of the EOSS programme (Chinn and others, 2005, 2012; Willsman and others, 2015). The first oblique aerial photography obtained for Brewster Glacier as part of the EOSS programme was captured in 1978, and it now provides a 38-year record of glacier behaviour. Prior to 1999, end-of-summer snowlines were generally lower than the long term average (positive mass balance), while higher snowlines (negative mass balance) have been observed more frequently since 2008, a trend consistent with other index glaciers in the Southern Alps.

\section{GLACIER OUTLINE AND SURFACE TOPOGRAPHY}

Glacier outlines and the surface topography of Brewster Glacier have been produced and refined on several occasions. The DEM most commonly used to characterise the surface topography of Brewster Glacier is based on a GPS survey of the glacier tongue and parts of the accumulation area carried out in January 1997 (Willis and others, 2009). Surface topography for the upper accumulation area was obtained by digitising 38 additional points from a Land Information New Zealand (LINZ) 1:50000 topographic map (NZMS260/G38), which was based on images obtained in a photogrammetric aerial survey in 1986. Willis and others (2009) used the same topographic map to define the glacier boundary, which has subsequently been updated using GPS measurements of the terminus in conjunction with the massbalance programme. Surface topography data obtained from GPS measurements are available from surveys conducted in 1997, 2005 and 2012 but the products do not contain full coverage of Brewster Glacier.

For the purpose of this study, a $15 \mathrm{~m}$ resolution DEM interpolated from 20-m contours derived from the photogrammetric aerial survey in 1986 (NZSoSDEM, Columbus and others, 2011) was used for all calculations involving elevation due to its complete representation of the surface. Comparison between the 15-m resolution DEM and the 2012 GPS survey exhibited elevation differences ranging from $-30 \mathrm{~m}$ at the terminus to $+30 \mathrm{~m}$ in the accumulation area. The glacier boundary considered representative of the observation period was defined using a near snow-free orthorectified (1.6 $\mathrm{m}$ RMSE) pan-sharpened Quickbird image from the Kiwlmage project acquired on 8 February 2011. To aid in the identification of the glacier boundary, oblique aerial photographs captured on 13 and 30 March 2011 that contained very little seasonal snow were also used. By using a fixed geometry, the glacier-wide mass-balance record we present is a reference-surface mass balance (Elsberg and others, 2001). The area of the glacier decreased from $2.54 \mathrm{~km}^{2}$ in 1986 to $2.03 \mathrm{~km}^{2}$ in 2011 , equivalent to a $21 \%$ decrease over the 25-year period (Fig. 1).

\section{GLACIOLOGICAL DATASET}

The current mass-balance programme on Brewster Glacier was initiated in February 2004, with the first year of measurements described by George (2005). As the programme evolved changes were made to the sampling methodology, resulting in variability in the glaciological dataset. To clarify how this has been managed, the main characteristics of the dataset are described in the following two sections. Further details about the programme over the period 2004-08 can be found in Stumm (2011), while Figure 1 shows the ablation stake and snow probing locations for the present mass-balance network. The winter mass balance referred to in this research represents the sum of accumulation and ablation over the winter season (Cogley and others, 2011), with the expectation that a small proportion of winter accumulation is lost to ablation. Likewise, the summer mass balance refers to the sum of accumulation and ablation over the summer season, with the ablation of snow and ice being the dominant component. The time system in which mass balance is calculated is from field surveys on floating calendar dates (a floating-date system), thus the duration of the mass-balance year varies slightly from year to year (Table 1).

\subsection{Winter mass-balance data}

At the beginning of the mass-balance programme, winter balance was determined at the end of the primary accumulation period (early to mid-November) from three snow pits 


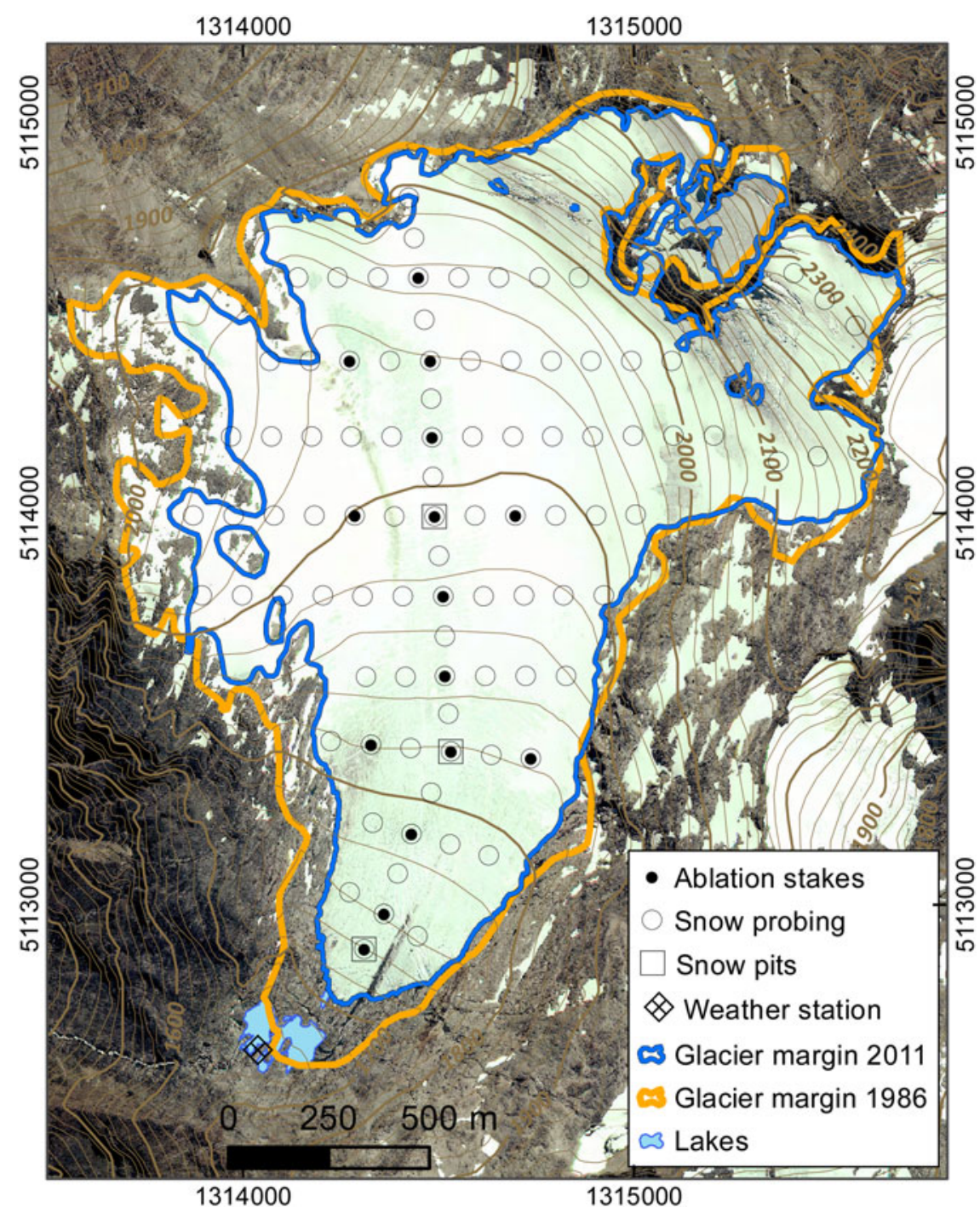

Fig. 1. The ablation stake network, probing and snow pit locations on Brewster Glacier. The glacier margins are shown for 1986 and 2011. The 2011 margin was digitized from a Quickbird image from 8 February 2011 and late summer aerial photographs on 13 and 30 March 2011. It should be noted that the probing locations shown above $2000 \mathrm{~m}$ a.s.l. are not regularly sampled, while those below typically are (see text for further details). Coordinates shown are defined using the New Zealand Transverse Mercator 2000 projection (NZTM2000).

along the central flowline of the glacier between 1700 and $1900 \mathrm{~m}$ a.s.l. (Fig. 1) and a limited number of snow depth measurements (Stumm, 2011) (Table 1). Snow pits were dug to the previous summer surface and density measurements were obtained. On some occasions snow density measurements were also obtained from a snow pit dug near the terminus. In November 2006, a Kovacs ice corer was also used to obtain an estimate of winter balance in the upper part of the glacier at an elevation of $2300 \mathrm{~m}$ a. s.l. (Fig. 1). From November 2007 and onwards an emphasis was placed on determining the spatial variability in snow depth, with extensive geo-located probing of snow cover carried out over the glacier (Fig. 1; probe locations), with at least one snow pit dug to obtain density measurements along the central flowline. Variability in the winterbalance measurements stems from the fact that the number of snow density measurements from snow pits varies from year to year, as does the number of snow depth measurements (Table 1). A key data deficiency is the under-sampling of snow density and depth on the steeper, south-west facing slopes in the upper accumulation area.

\subsection{Summer mass-balance data}

Summer mass balance has been obtained by measuring changes in the height of a network of PVC stakes drilled into the glacier using a Heucke steam ice drill. On most occasions, ablation stakes were drilled in conjunction with the end of winter field measurements (early to mid-November), and re-surveyed at the end of summer (mid to end of March). The network was initially extensive, with over 30 ablation stakes drilled in December 2004 at $100 \mathrm{~m}$ intervals along the central flowline, as well as four transects extending across the central flowline (George, 2005; Stumm, 2011). In November 2008, the stake network was reduced to permit a smaller number of people to complete the field measurements, with further minor changes to their locations made in November 2014 (Fig. 1).

Like the winter mass-balance measurements, there is also sampling variability in the ablation stake data over the observational period (Table 1). The most significant differences in data collection occurred during the 2006-08 mass-balance period, when the network of stakes was used primarily for the calculation of annual balance rather than summer 
Table 1. Observational data for each mass balance $(M B)$ year, including the observation type, start and end date of measurements, the method used to obtain the data and the number of measurements. Each MB year contains three rows of information, with the density and depth data used primarily for winter balance, while the stake data are either used for summer or annual balance

\begin{tabular}{|c|c|c|c|c|c|}
\hline MB year & Observation type & Start date & End date & Method & Number \\
\hline 2005 & Density & 18 Dec 2004 & & Snow pit & 3 \\
\hline 2005 & Depth & 18 Dec 2004 & & Snow pit & 3 \\
\hline 2005 & Summer balance & 18 Dec 2004 & 21 Mar 2005 & Stake & 31 \\
\hline 2006 & Density & 07 Nov 2005 & & Snow pit & 4 \\
\hline 2006 & Depth & 07 Nov 2005 & & Snow pit & 4 \\
\hline 2006 & Annual balance & 22 Mar 2005 & 13 Feb 2006 & Stake & 31 \\
\hline 2007 & Density & 20 Nov 2006 & & Snow pit & 4 \\
\hline 2007 & Depth & 20 Nov 2006 & & Snow pit & 4 \\
\hline 2007 & Annual balance & 14 Feb 2006 & 23 Mar 2007 & Stake & 33 \\
\hline 2008 & Density & 16 Nov 2007 & & Snow pit & 3 \\
\hline 2008 & Depth & 16 Nov 2007 & & Probing & 125 \\
\hline 2008 & Annual balance ${ }^{\mathrm{a}}$ & 24 Mar 2007 & 20 Apr 2008 & Stake & 32 \\
\hline 2009 & Density & 12 Nov 2008 & & Snow pit & 4 \\
\hline 2009 & Depth & 13 Nov 2008 & & Probing & 81 \\
\hline 2009 & Summer balance & 12 Nov 2008 & 18 Mar 2009 & Stake & 9 \\
\hline 2010 & Density & 19 Nov 2009 & & Snow pit & 3 \\
\hline 2010 & Depth & 18 Nov 2009 & & Probing & 87 \\
\hline 2010 & Summer balance & 18 Nov 2009 & 28 Mar 2010 & Stake & 13 \\
\hline 2011 & Density & 24 Oct 2010 & & Snow pit & 3 \\
\hline 2011 & Depth & 21 Oct 2010 & & Probing & 55 \\
\hline 2011 & Summer balance & 23 Oct 2010 & 12 Mar 2011 & Stake & 11 \\
\hline 2012 & Density & 27 Oct 2011 & & Snow pit & 2 \\
\hline 2012 & Depth & 29 Nov 2011 & & Probing & 28 \\
\hline 2012 & Summer balance & 29 Nov 2011 & 21 Mar 2012 & Stake & 15 \\
\hline 2013 & Density & 30 Oct 2012 & & Snow pit & 2 \\
\hline 2013 & Depth & 29 Oct 2012 & & Probing & 45 \\
\hline 2013 & Summer balance & 31 Oct 2012 & 21 Mar 2013 & Stake & 14 \\
\hline 2014 & Density & 12 Nov 2013 & & Snow pit & 2 \\
\hline 2014 & Depth & 12 Nov 2013 & & Probing & 60 \\
\hline 2014 & Summer balance & 01 Nov 2013 & 08 Apr 2014 & Stake & 14 \\
\hline 2015 & Density & 01 Dec 2014 & & Snow pit & 1 \\
\hline 2015 & Depth & 01 Dec 2014 & & Probing & 79 \\
\hline 2015 & Summer balance & 01 Dec 2014 & 17 Mar 2015 & Stake & 15 \\
\hline
\end{tabular}

a Annual balance calculated using the method described by Stumm (2011; see pg. 284-285).

balance (Stumm, 2011). At other times, ablation stakes were not steam drilled at all locations due to time constraints and/ or not re-surveyed at the end of summer because they had either melted out of the ice or were completely lost.

\section{METHODS}

\subsection{Calculation of winter mass balance}

\subsubsection{Snow density}

The density of snow at the end of winter was obtained from snow pits from at least one, and up to four, locations on the glacier (Table 1). To assess whether elevation is a control on snow density, a comparison of mean snow densities from all individual snow pits during the programme was made. A one-way analysis of variance (ANOVA) for all years except 2006 and 2010 yields a $P$-value $=0.26$, enabling us to reject the null hypothesis that mean snow densities are significantly different from each other. Only snow densities measured to calculate mass balance in 2007 ( $P$-value $<$ $0.01)$ and $2011(P$-value $<0.05)$ display significant differences to other years. The mean snow density from all years is $492 \mathrm{~kg} \mathrm{~m}^{-3}$, with a standard deviation of $36 \mathrm{~kg} \mathrm{~m}^{-3}$. In view of the difficulty of obtaining significant spatial or temporal variations of snow density based on the observational dataset, it was concluded that the best approach to estimate snow density $\left(\rho_{\mathrm{s}}\right)$ was to rely solely on the mean snow density $\mu_{t}^{\rho_{s}}$ in any given year $t$ and to use an uncertainty of $36 \mathrm{~kg} \mathrm{~m}^{-3}$ for error propagation in the mass-balance calculation.

\subsubsection{Creating a snow-depth index}

To develop a robust method to estimate winter balance, we searched for a linear predictor capable of explaining the variance in snow depth obtained from the snow pit and snow probing measurements. In alpine terrain, snow depth is usually found to correlate reasonably well with elevation, which is also the case on Brewster Glacier (Fig. 2a). For each year, the snow depth data exhibit a linear correlation with elevation below 2000 ma.s.l. that is significant at the $95 \%$ confidence level for all years except $2004(P$-value $=0.26)$ and 2005 $(P$-value $=0.10)$, when the number of snow depth samples obtained were small. On average, elevation is found to explain $73 \%$ of the variance in snow depth below $2000 \mathrm{~m}$ a.s. I. The small number of data points above $2000 \mathrm{~m}$ a.s.l. suggests there is a decline in the snow depth gradient (Fig. 2a), which compromises the linear regression approach to model snow depth across the entire elevation range of Brewster Glacier.

Despite this limitation, Figure $2 \mathrm{a}$ shows there is a coherency in the spatial structure of snow depth gradient from year to year, which is used as justification to search more thoroughly for a single spatial predictor against which data 
a

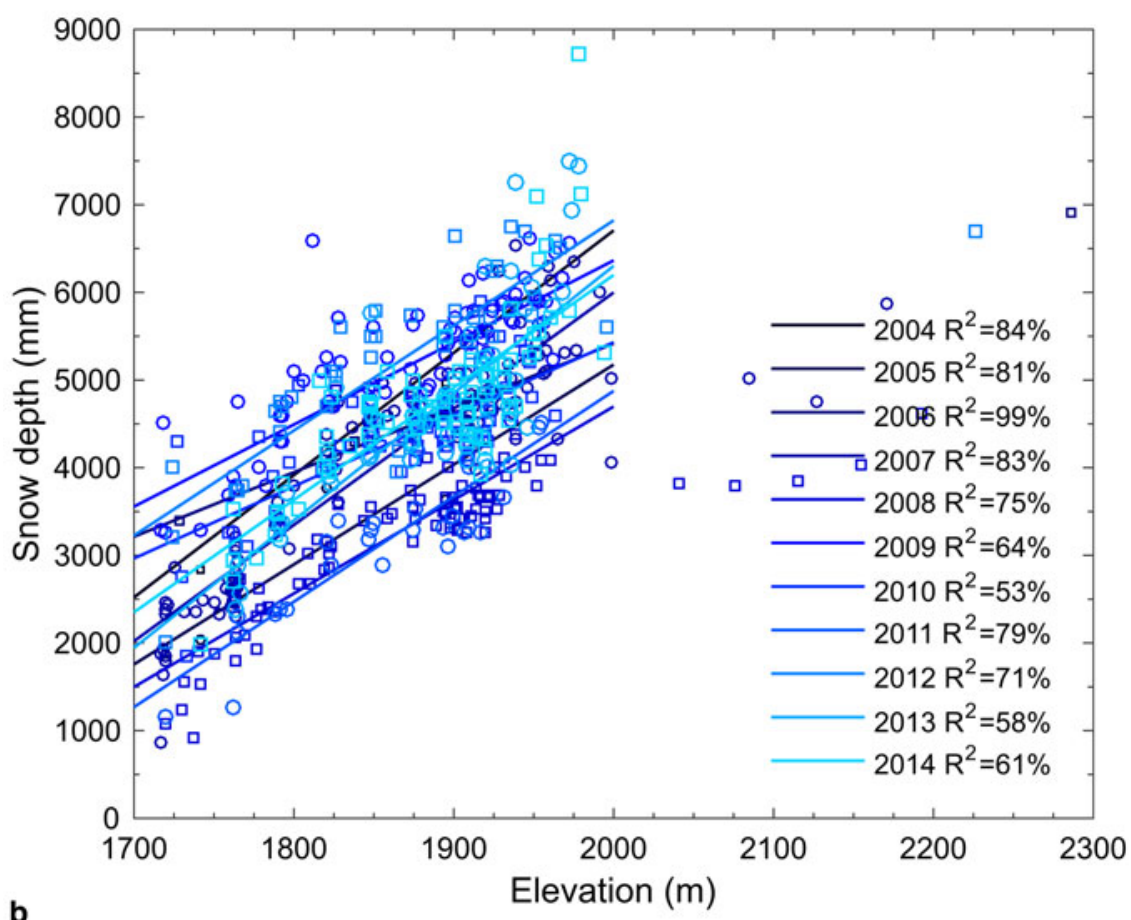

b

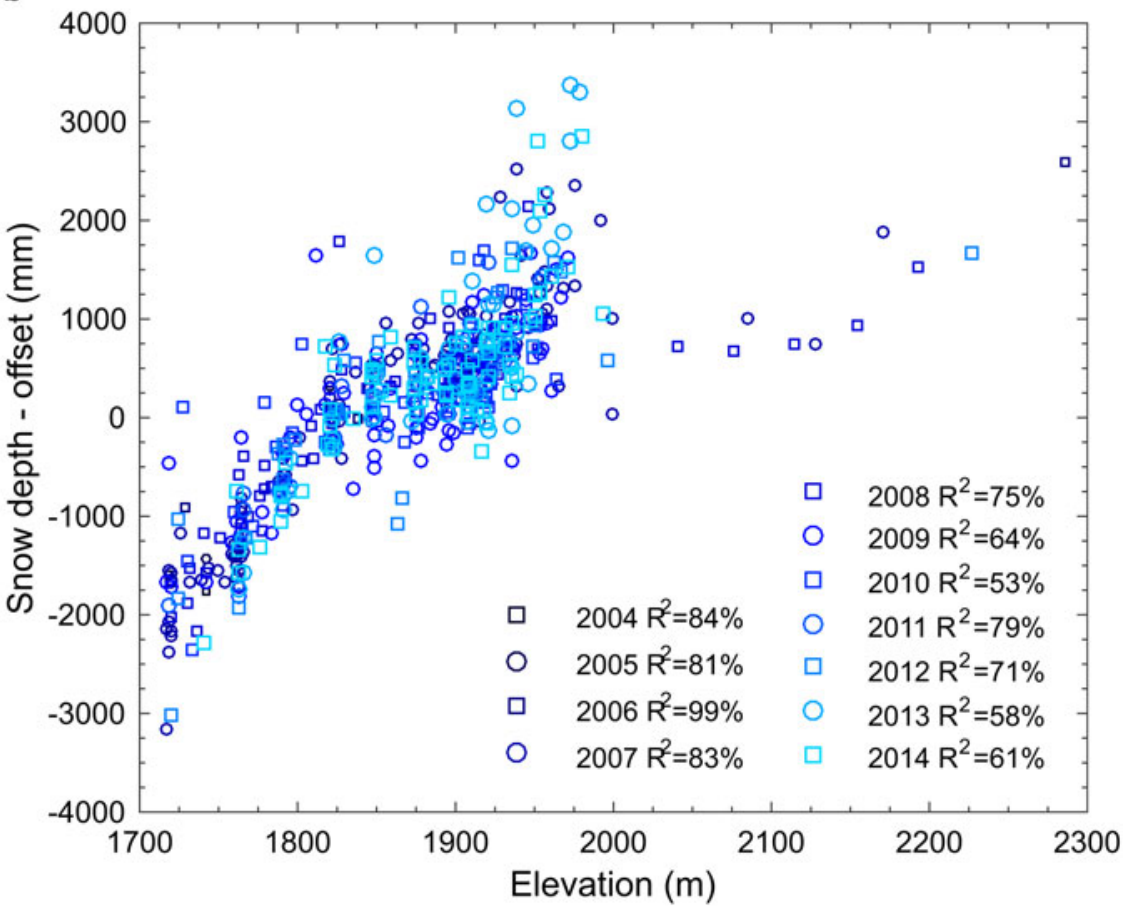

Fig. 2. (a) The relationship between snow depth and elevation. The linear regressions are computed over an elevation range between 1700 and $2000 \mathrm{~m}$ a.s.l. (b) Snow depth data for each year are offset using the regressed value at an elevation of $1850 \mathrm{~m}$ a.s.l.

from individual years might be regressed. To build a model that removes the variability associated with differences in total accumulation from year to year, the linear regression models of each individual year are used to offset the snow depth measurements based on the mid-elevation value of each regression (i.e. $1850 \mathrm{~m}$ a.s.l.). The mid-elevation is the mid-point of the elevation range (1700-2000 $\mathrm{m}$ a.s.I.) over which the linear regression models between snow depth and elevation are made. Using this approach we subtract the regression value at $1850 \mathrm{~m}$ a.s.l. from the snow depth data for each year, which yields a synthetic dataset that shifts all snow depth information to a common origin (Fig. 2b). The consistency of the scatter plot is explained by the limited variance associated with the gradient (mean $\mu=11.4 \mathrm{~mm} \mathrm{~m}^{-1}$, standard deviation $\sigma=2.3 \mathrm{~mm} \mathrm{~m}^{-1}$ ) and suggests that the snow cover at the end of the winter exhibits a coherent spatial structure and is primarily affected by year to year variability in the magnitude of winter balance.

To characterise and model the spatial structure of snow depth, we assume that the offset snow depth data stem from the realisation of a random function (Wackernagel, 2003), which we define here as a snow depth index (SDI). This provides us with a platform from which to apply a multi-variate geostatistical approach to resolve the spatial variability in snow depth. To guarantee first- and secondorder stationarity assumptions are met for variogram 

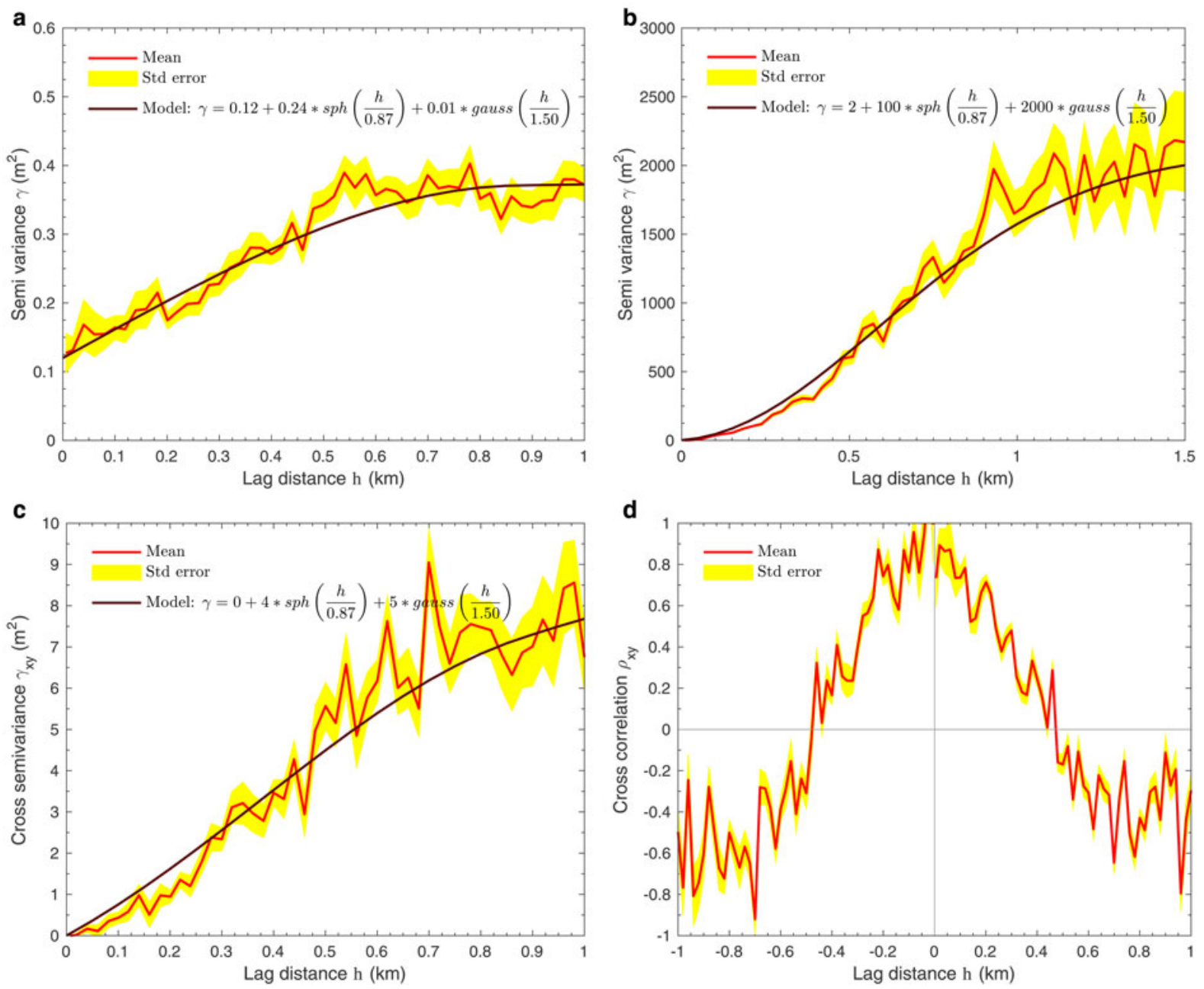

Fig. 3. Experimental semi-variograms for (a) $S D I$ and (b) elevation, along with their variogram models. The nugget of the semi-variogram is the intercept at 0-lag. It corresponds to the collocated variance present in the dataset resulting from short-scale variations not captured by the sampling network, measurement errors, and, in the present case, variance inherent to data collected at different dates. The range of the semi-variogram is the distance at which the sill or plateau is reached and is indicative of the loss of spatial auto-correlation between measurements separated by such distance. (c) Cross semi-variogram associated with both variables with fitted linear model of coregionalization. (d) Ergodic cross-correlogram computed for both $+\mathrm{h}$ and $-\mathrm{h}$ directions to support a complete picture of spatial covariation (Rossi and others, 1992).

computation and subsequent kriging (Wackernagel, 2003, p. 51), the SDI and elevation covariates are de-trended using a two-dimensional (2-D) hyperplane. Figures $3 a, b$ demonstrate that the semi-variograms for SDI and elevation exhibit a marked spatial structure, with the SDI range approaching $500 \mathrm{~m}$, while the range in elevation is almost twice as large $(\sim 1000 \mathrm{~m})$. The SDI semi-variogram exhibits a nugget of $0.12 \mathrm{~m}^{2}$, which corresponds to the collocated variance associated with data from different dates. If all measurements had been collected on the same date, this nugget would capture the measurement error associated with the small-scale effects of snow depth variability $(\sim 0.35 \mathrm{~m})$.

The semi-variogram models are computed to enable a linear model of coregionalization (LMC) to be utilised (Goovaerts, 1998), with the purpose of building a cokriging system capable of predicting SDI across the entire surface of Brewster Glacier. The cross-semivariance and cross-correlogram shown in Figures 3c, d demonstrate that, in addition to the correlation at a glacier-wide scale (Fig. 2), SDI and elevation display a significant spatial cross-correlation structure. By taking advantage of the $15 \mathrm{~m}$ resolution DEM that offers a high number of elevation samples, co-kriging can be utilised to obtain a robust prediction of $S D I$ variability, which is expected to result in smaller error variances than univariate kriging or other interpolation methods (Goovaerts, 1998). We used the Geostatistical Analyst Toolbox in ArcGIS v10.2 to apply co-kriging to the SDI samples (Fig. 4a), using the DEM as a cofactor (Fig. 4b). A smooth surface is achieved by using between 5 and 200 samples within a search neighbourhood of $750 \mathrm{~m}$ to accommodate the range of both covariates. The outcome of this approach yields a map of prediction and standard error of the regionalised $S D I$, referred to as $S D I_{C K}$ and $\sigma_{C K}^{S D I}$, respectively (Figs $4 \mathrm{c}, \mathrm{d}$ ).

\subsubsection{Using the SDI to determine winter mass balance} There is a robust relationship between $S D I_{C K}$ and snow depth for each winter mass-balance year on record (Fig. 5). The years with only three-four snow depth measurements (2004-06), as determined from snow pits, exhibit significant determination coefficients $(P$-value $<0.01)$. All other years have very high and significant correlations $\left(P\right.$-values $\left.<10^{-11}\right)$, which confirm that $S D I_{C K}$ is a strong predictor of snow depth. On average, $S D I_{C K}$ explains $89 \%$ of the variance in snow depth, which is a considerable improvement compared with using 

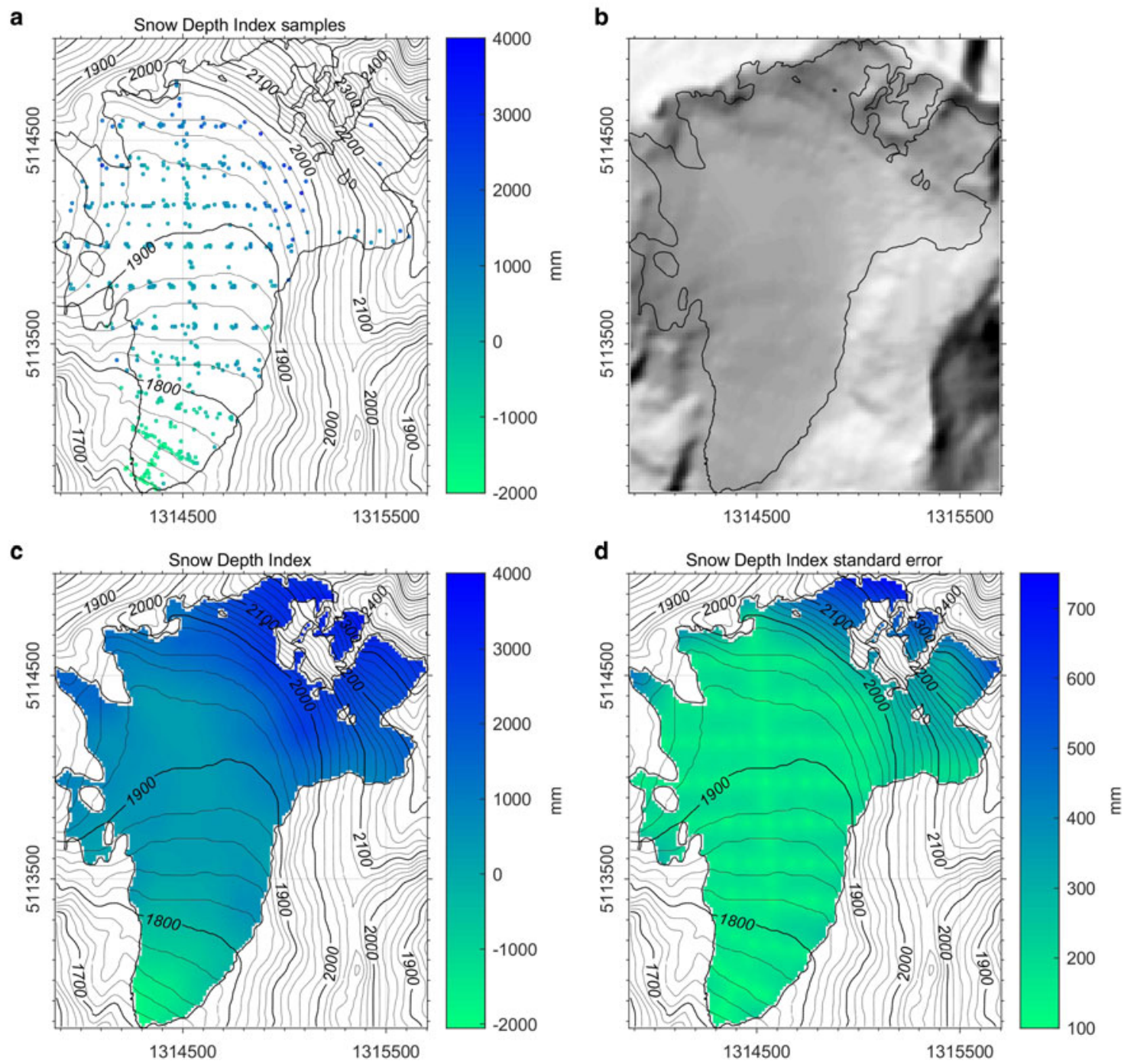

Fig. 4. (a) Set of $S D I$ samples cokriged with elevation from the $D E M$ in (b). (c) Resulting $S D I_{C K}$ map and (d) associated kriging standard error $\sigma_{C K}^{S D I}$.

elevation as a predictor (Fig. 2a). Furthermore, the consistent linear relationship between $S D I_{C K}$ and snow depth does not break down at higher elevations, which is observed to occur when using elevation as the independent variable. Although $\sigma_{C K}^{S D I}$ remains high due to the distance to support points (Fig. 4d), it is reduced by benefiting from the secondary information of elevation available in this area.

Our new method to spatially interpolate snow depth is not dependent on data from individual years but instead uses the $S D I_{C K}$ predictor. The winter balance years with sparse data for which interpolation might have been compromised and subject to artefacts can now be spatially interpolated in a consistent manner. The spatial interpolation for any individual year exploits data from the entire record, which is important in the interpolation of snow depth at higher elevations, while also useful in spreading measurement errors. The adjustment of mass-balance data in this manner shares commonalities with the approaches used by Lliboutry (1974) and Eckert and others (2011), which are examined further in Section 6.7.

Finally, the co-kriging standard error map provides a means to display the statistical uncertainties associated with snow depth that can be propagated to estimate winter balance $\left(b_{\mathrm{w}}\right)$. In practice, in any given year $(t)$ and regardless of the sparsity of snow depth data, an estimate of the snow depth random function $\hat{D}_{\mathrm{t}}$ is obtained via linear regression between observations and $S D I_{C K}$ as:

$$
\hat{D}_{\mathrm{t}}=\max \left(\left\{s_{w_{t}} S D I_{C K}+O_{w_{t}}, 0\right\}\right)
$$

where $s_{w_{t}}$ and $o_{w_{t}}$ are the slope and intercept of the regression $\left(w\right.$, winter balance). This yields a map of winter balance $\left(b_{\mathrm{w}}\right)$ for any given year $(t)$ as:

$$
b_{w_{t}}=\mu_{t}^{\rho_{s}} \hat{D}_{t}
$$

The standard error in winter balance for any given year $(t)$ $\sigma_{b_{w_{t}}}$ is obtained via error propagation:

$$
\sigma_{b_{w_{t}}}=\sqrt{\hat{D}_{t} \times 0.036^{2}+\mu_{t}^{\rho_{s}} \times\left(s_{w_{t}} \sigma_{C K}^{S D I}\right)^{2}}
$$

From the map and standard error of winter balance, the glacier-wide surface winter balance $\left(B_{\mathrm{w}}\right)$ and associated standard error $\sigma_{B_{w}}$ are computed as arithmetic and quadratic means for any given year $(t)$, respectively:

$$
\left\{\begin{array}{c}
B_{w_{t}}=\overline{b_{w_{t}}} \\
\sigma_{B_{w_{t}}}=\sqrt{\overline{\sigma_{b_{w_{t}}^{2}}}}
\end{array}\right.
$$




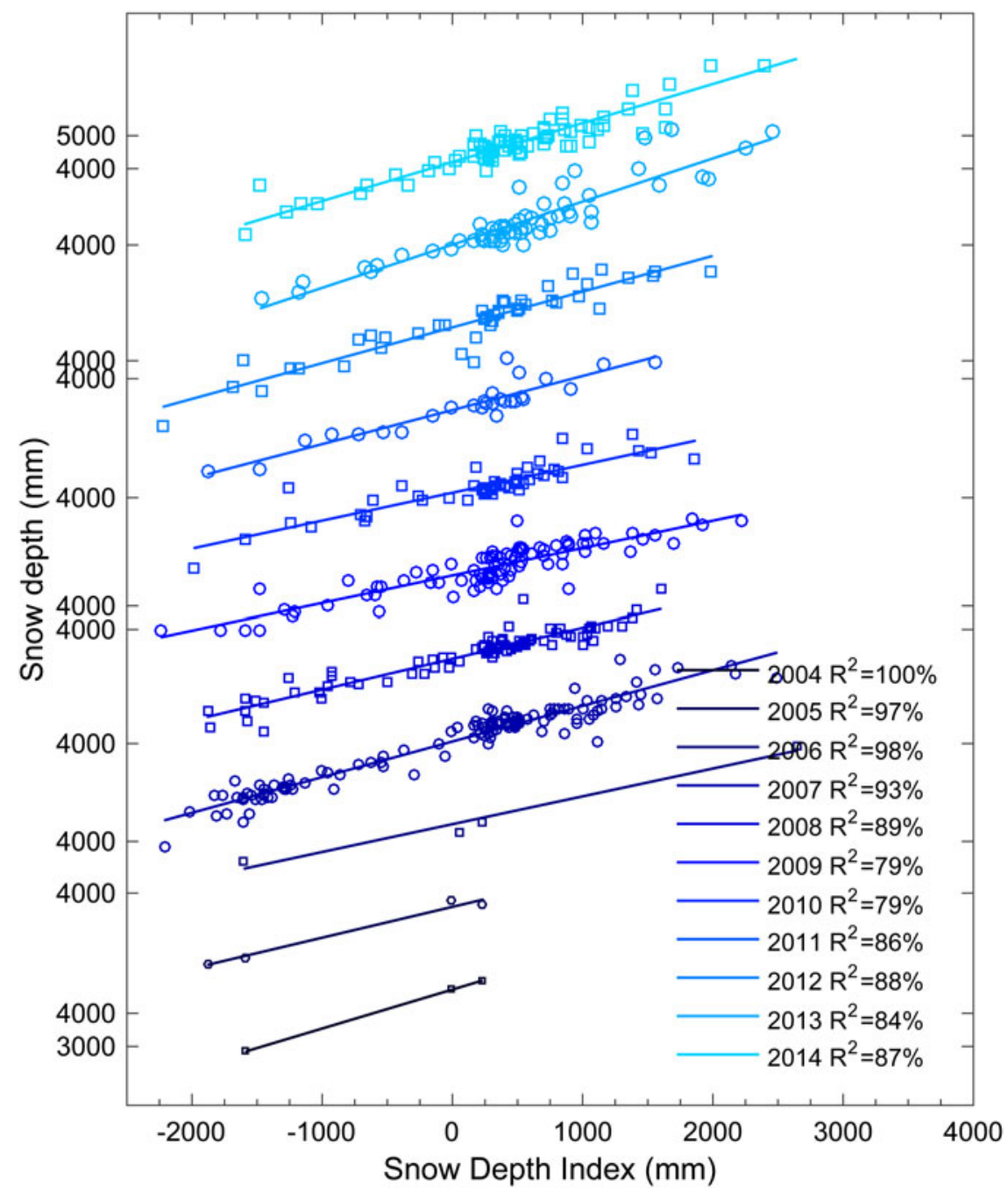

Fig. 5. Measured snow depth versus SDI. Years are offset for clarity.

\subsection{Calculation of summer mass balance}

\subsubsection{Creating a mean summer balance index}

Ablation of snow and ice is the main component of the summer balance $\left(b_{s}\right)$, with measurements from ablation stakes available to calculate $b_{s}$ for all years except 2006, 2007 and 2008. Summer balance is calculated from observed changes in ablation stake height in relation to the surface for any given year $(t) S H_{t}\left(\boldsymbol{x}_{i}\right)$ at a location $\boldsymbol{x}_{i}$ to $b_{\mathrm{s}}$ in w.e. Using the mapped snow depth in the previous year $\hat{D}_{t-1}$ it becomes possible to estimate $b_{\mathrm{s}}$ as follows:

$$
b_{s_{t}}\left(\boldsymbol{x}_{i}\right)=\left\{\begin{array}{c}
-\mu_{t-1}^{\rho_{s}} \hat{D}_{t-1}\left(\boldsymbol{x}_{i}\right)-\rho_{i}\left(S H_{t}\left(\boldsymbol{x}_{i}\right)-\hat{D}_{t-1}\left(\boldsymbol{x}_{i}\right)\right), \\
\text { if } S H_{t}\left(\boldsymbol{x}_{i}\right)>\hat{D}_{t-1}\left(\boldsymbol{x}_{i}\right) \\
-\mu_{t-1}^{\rho_{s}} \hat{D}_{t-1}\left(\boldsymbol{x}_{i}\right), \text { otherwise }
\end{array}\right.
$$

where $\rho_{i}$ is the density of ice $\left(900 \mathrm{~kg} \mathrm{~m}^{-3}\right)$. Following the same approach as for snow depth, elevation was initially considered as a predictor for summer balance. Correlations between summer balance and elevation proved relatively weak and sometimes not significant, with an average $R^{2}=$ $54 \%$ (Fig. 6a). Alternatively, substantially better correlations are obtained between summer balance and $S D I_{C K}$, with an average $R^{2}=73 \%$ (Fig. $6 \mathrm{~b}$ ). Similar to the probing data, a synthetic dataset combining all summer balance estimates is obtained by deducting, for each year, the value of a linear regression model between $S D I_{C K}$ and summer balance at $S D I_{C K}=400 \mathrm{~mm}$. This corresponds approximately to the $1850 \mathrm{~m}$ a.s.l. elevation used to offset the snow depth data. However, unlike the snow depth data obtained from snow pit and probing measurements, ablation stakes are always drilled at the same geographic location. As such, all summer balance measurements cannot be used together in a geostatistical approach because of collocation (i.e. lag $=0$ ). Instead, the offset summer balance estimates are averaged to derive a single mean summer balance index $(M S B I)$ at each stake location. The MSBI takes advantage of the statistical averaging, which yields a reduced dispersion and a strong, significant correlation with $S D I_{C K}$ $\left(R^{2}=85 \%, P\right.$-value $\left.<0.01\right)$ (Fig. 6b).

Figures 7a, b show the semi-variogram analysis for detrended $\mathrm{MSBI}$ and $S D I_{C K}$. Both covariates exhibit a marked spatial structure, with a similar range of $\sim 500 \mathrm{~m}$. Spatial co-variation is significant as shown on the cross semi-variogram and cross-correlogram (Figs 7c, d). Given the strong correlation also shown between both variables (Fig. 6b), a co-kriging approach is applied to spatially interpolate $\mathrm{MSBI}$ using $S D I_{C K}$ as a co-variate. This yields a spatial predictor for summer balance $\left(M S B I_{C K}\right)$, which 

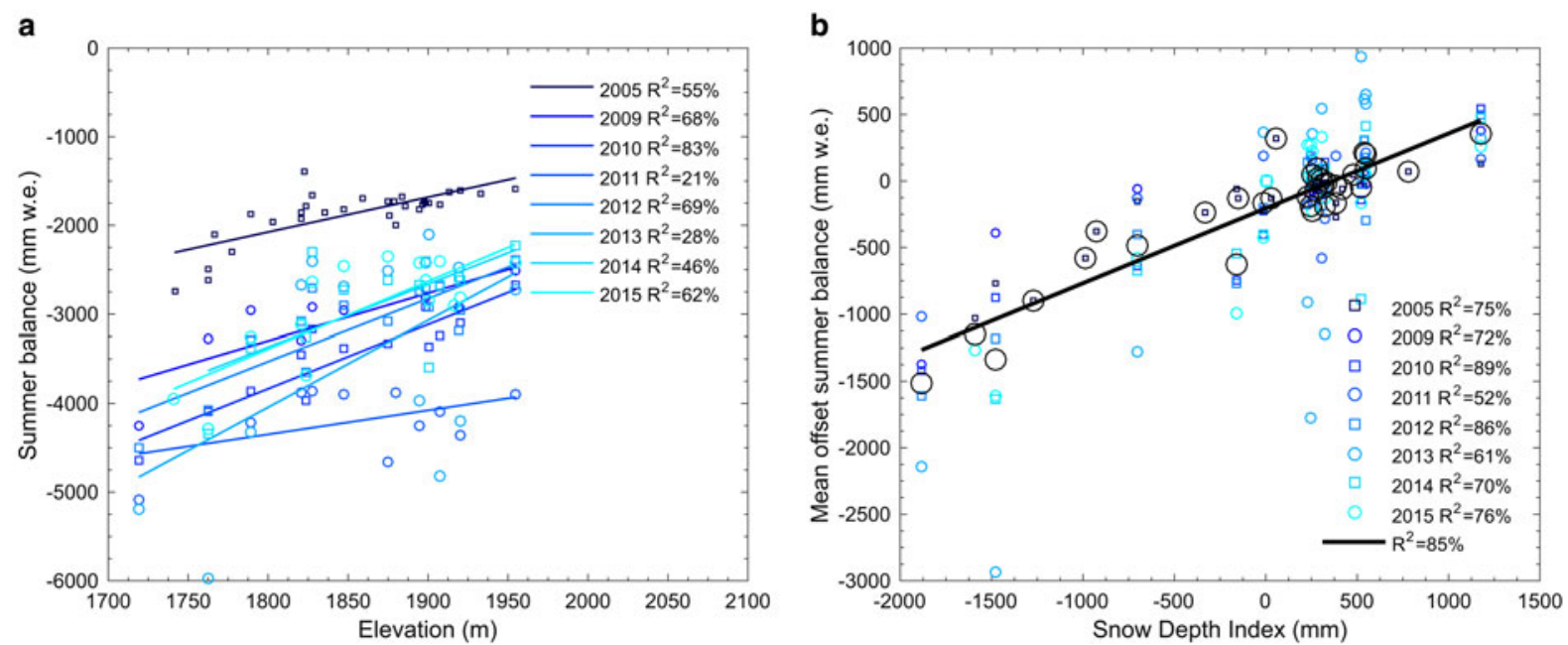

Fig. 6. (a) Correlation between summer ablation and elevation at the stakes. (b) Correlation between summer ablation and $S D I_{C K}$. Ablation data for each year are offset using the regressed value at elevation $S D I_{C K}=400 \mathrm{~mm}$. Black circles are the average ablation at each stake.
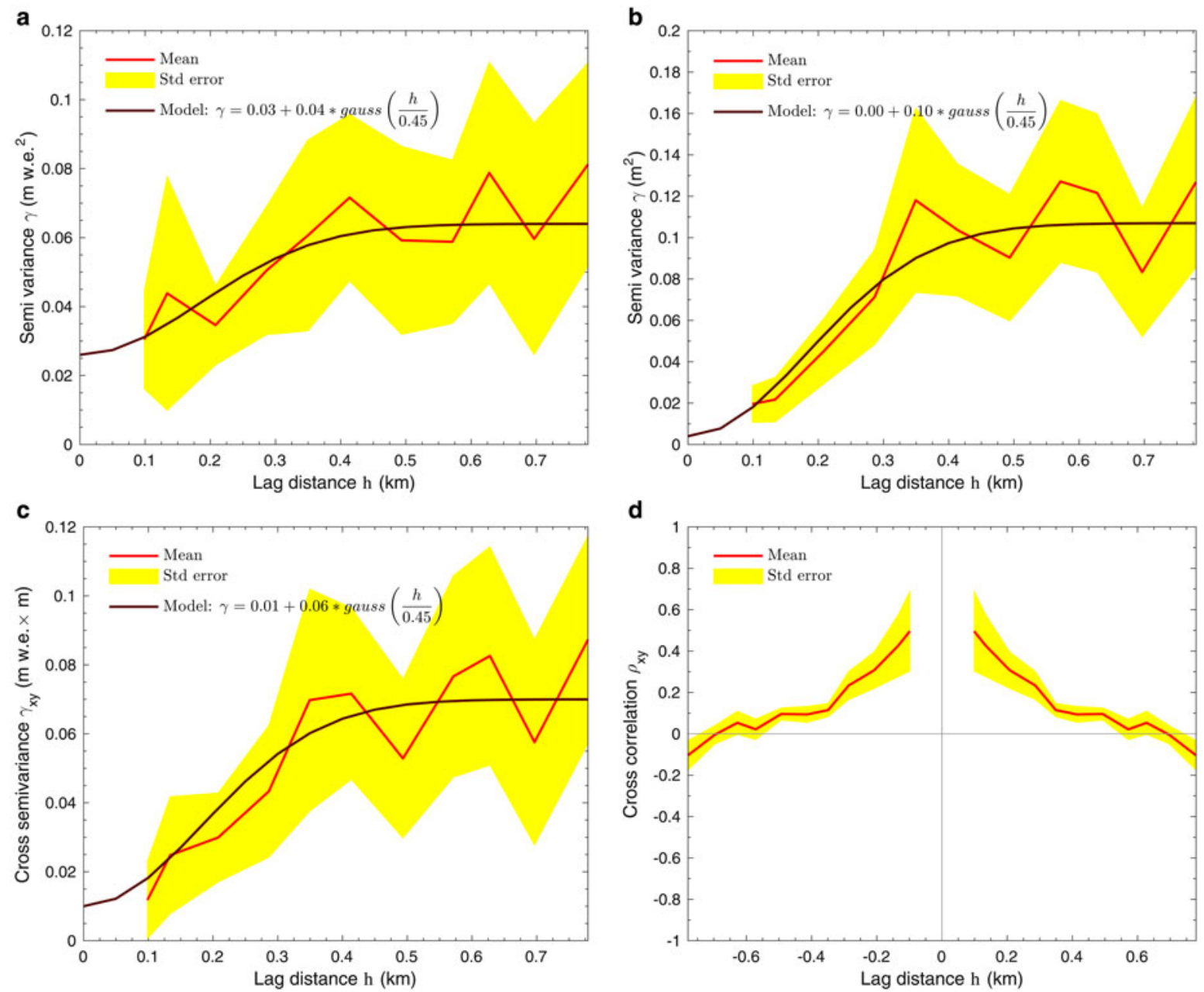

Fig. 7. Experimental semi-variograms for (a) $M S B I$ and (b) $S D I_{C K}$, along with their variogram models. (c) Cross semi-variogram associated with both variables with fitted linear model of coregionalization. (d) Ergodic cross-correlogram computed for both $+h$ and $-h$ directions to support a complete picture of spatial covariation (Rossi and others, 1992).

supports the interpolation of summer balance in regions that do not contain ablation stakes, thus reducing the standard error $\sigma_{C K}^{M S B I}$ (Fig. 8). All samples within a radius of $2000 \mathrm{~m}$ are used to interpolate a smooth $M S B I_{C K}$ surface. Although this radius exceeds the range of both covariates it is required to enable $M S B I$ to be extrapolated over the whole surface but it comes at the expense of generating relatively large errors far from support points.

\subsubsection{Using MSBI to determine summer mass balance} The regression of summer balance values at ablation stake locations versus $M S B I_{C K}$ for each year is shown in Figure 9. 
a

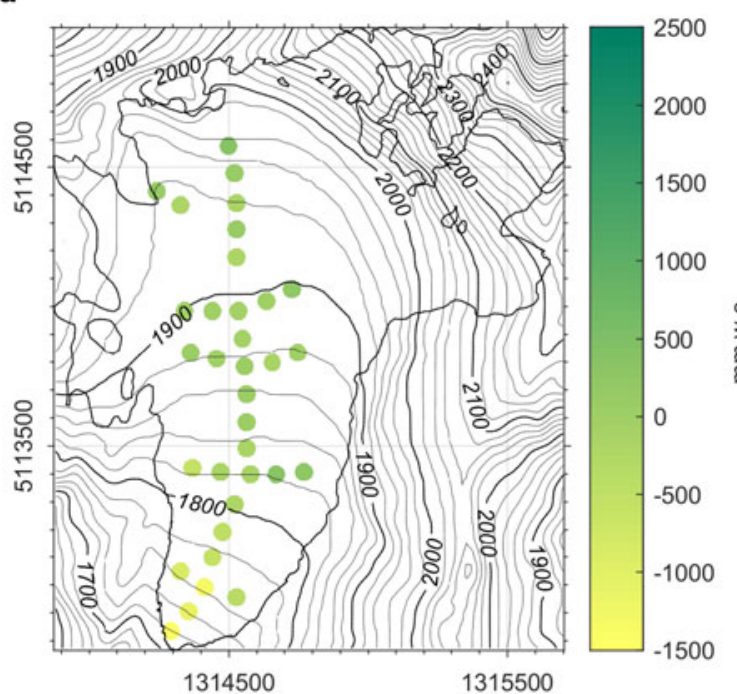

C

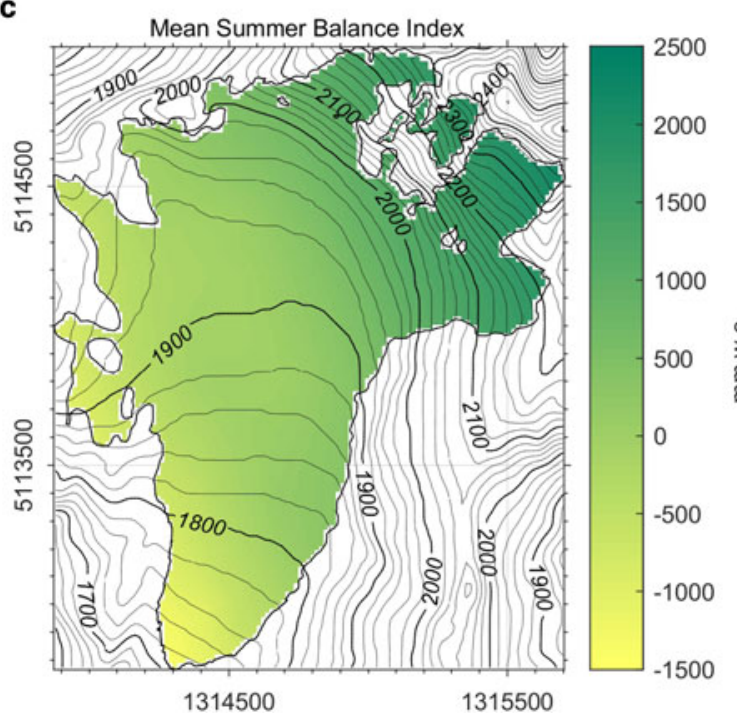

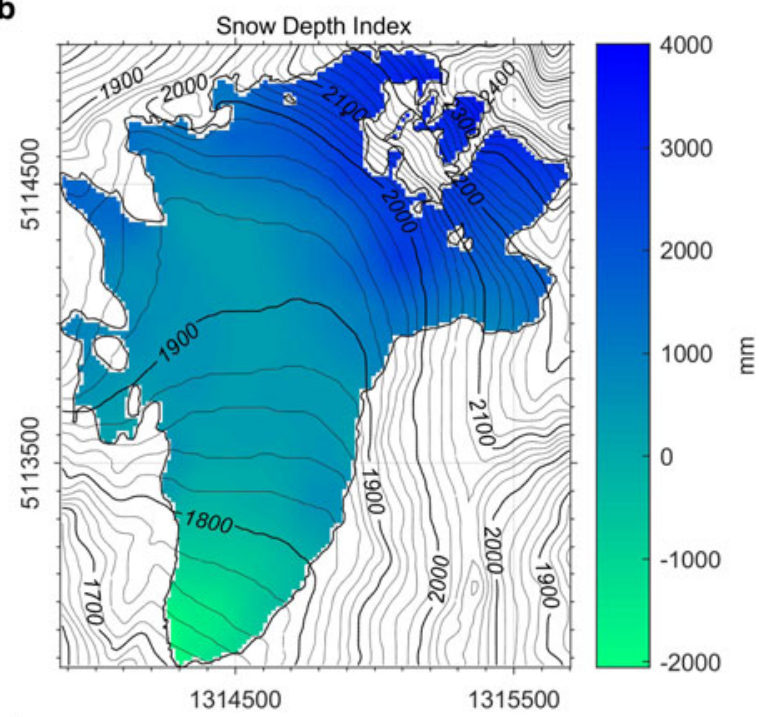

d

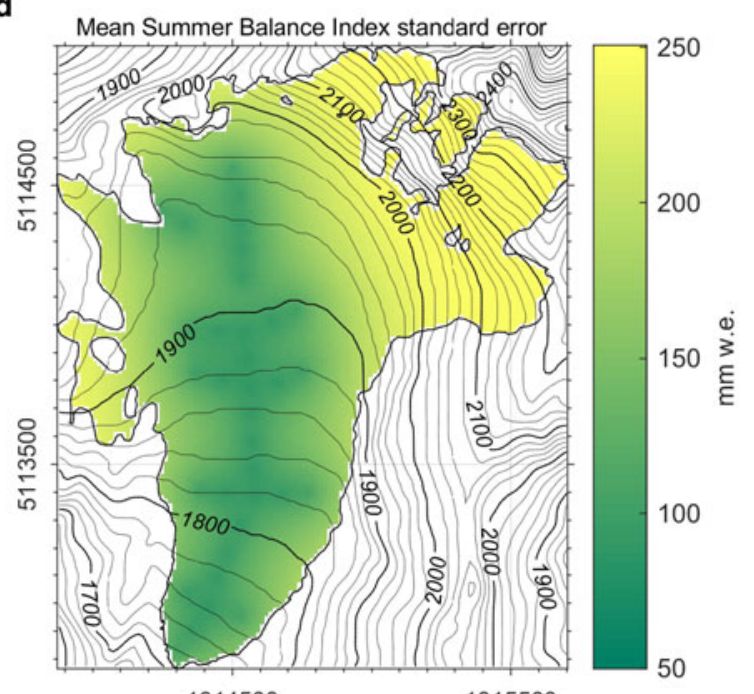

1314500

1315500

Fig. 8. (a) Set of $M S B I$ samples cokriged with $S D I_{C K}$ in (b). (c) Resulting $M S B I_{C K}$ map and (d) associated kriging standard error $\sigma_{C K}^{M S B I}$.

It demonstrates that the linear relationship between $M S B I_{C K}$ and summer balance is robust for individual years, with all having strong and significant correlations $(P$-values $<0.01)$. This verifies that $M S B I_{C K}$ is a robust predictor of summer balance, explaining on average $78 \%$ of the variance, which is vastly improved compared with only using elevation.

Using the same approach as for snow depth (and winter balance), summer balance is obtained via regression of the ablation stake observations over an individual summer with $M S B I_{C K}$. This allows an adjustment of the observations and a distribution of observational errors, while minimizing inter- and extrapolation artefacts. For any given year $(t)$ a map of summer balance $\left(b_{s_{t}}\right)$ is obtained via linear regression between observations and $M S B I_{C K}$ as:

$$
b_{s_{t}}=\min \left(\left\{s_{s_{t}} M S B I_{C K}+o_{s_{t}}, 0\right\}\right)
$$

where $s_{S_{t}}$ and $o_{s_{t}}$ are the slope and intercept of the regression $(s$, summer balance). The standard error in summer balance for any given year $(t) \sigma_{b_{s_{t}}}$ is obtained by:

$$
\sigma_{b_{s_{t}}}=s_{s_{t}} \sigma_{C K}^{M S B I}
$$

From the map and standard error of summer balance, the glacier-wide surface summer balance $\left(B_{S}\right)$ and associated standard error $\sigma_{B_{s}}$ are computed by arithmetic and quadratic mean for any given year $(t)$, respectively:

$$
\left\{\begin{array}{c}
B_{s_{t}}=\overline{b_{s_{t}}} \\
\sigma_{B_{s_{t}}}=\sqrt{\overline{\sigma_{b_{s_{t}}}^{2}}}
\end{array}\right.
$$

\subsection{Calculation of annual mass balance}

5.3.1. Years with summer and winter mass-balance measurements

For all years except 2006, 2007 and 2008 a map of annual balance $\left(b_{\mathrm{a}}\right)$ is obtained by summing the map of summer balance $\left(b_{\mathrm{s}}\right)$ in year $t$ with that of winter balance $\left(b_{\mathrm{w}}\right)$ in year $t-1$ :

$$
b_{a_{t}}=b_{w_{t-1}}+b_{s_{t}}
$$

The independence of errors in $b_{\mathrm{w}}$ and $b_{\mathrm{s}}$ is tested by examining the residuals of cross validation of the co-kriging models for $S D I_{C K}$ and $M S B I_{C K}$. The sets of cross-validation residuals for both spatial predictors on collocated support points $(n=34)$ fail the Anderson-Darling test $(P$-value $=0.98$ and 0.49 , respectively), indicating that both sets of residuals are 


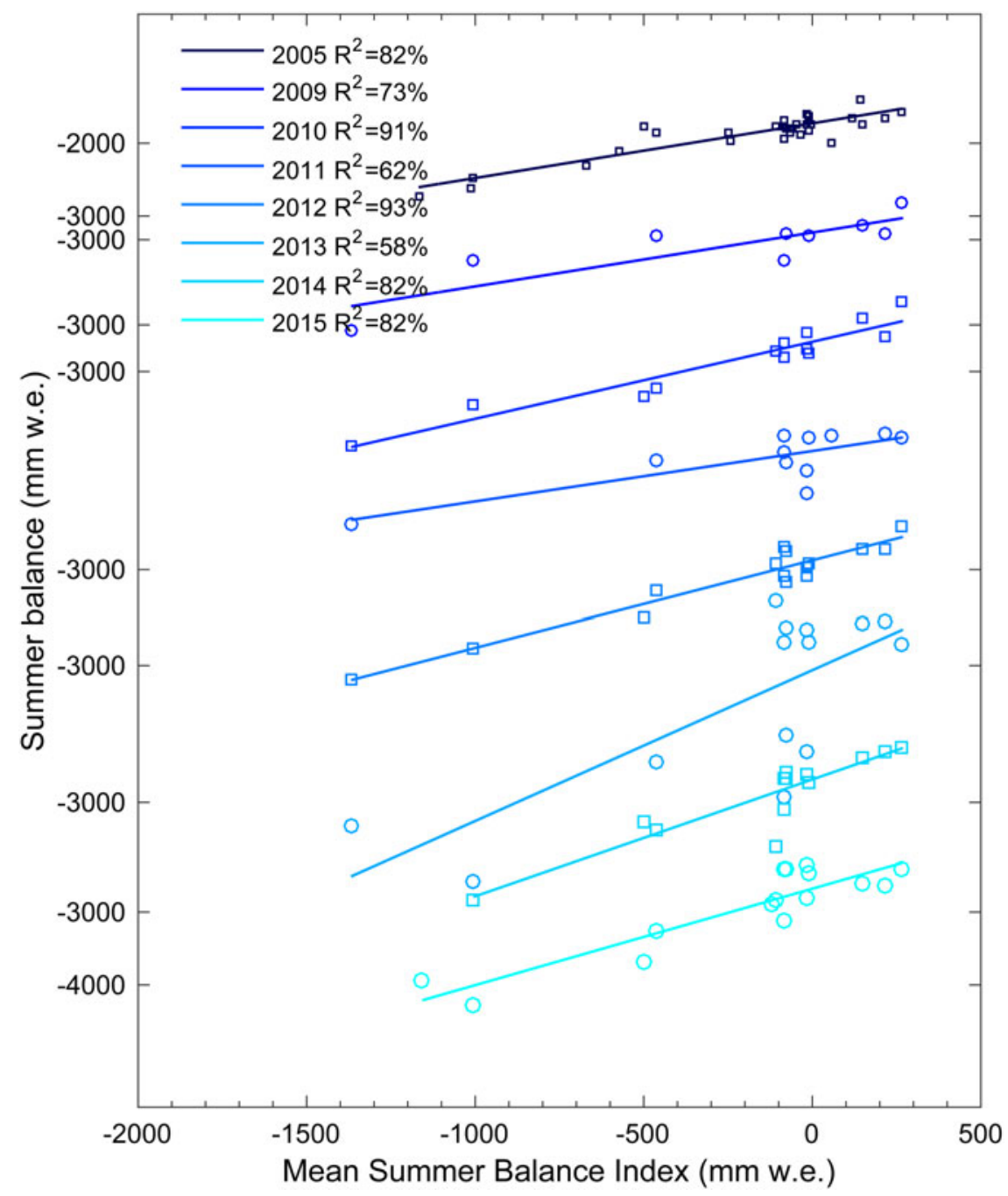

Fig. 9. Summer balance versus MSBI. Years are offset for clarity.

from a population with a normal distribution. An insignificant Pearson correlation coefficient $(r=-0.17, P$-value $=0.34)$ and no visible pattern in the scatter plot could be taken to suggest independence between both sets of residuals. However, independence between both sets of residuals is confirmed at the $99 \%$ confidence level by applying the Hilbert-Schmidt Independence Criterion (HSIC, Gretton and others, 2005) (test statistic $=0.2702<$ test threshold $=$ 0.5424). The standard error in the mass-balance map for any given year $(t)$ is therefore obtained by Gaussian error propagation by:

$$
\sigma_{b_{a_{t}}}=\sqrt{\sigma_{b_{s_{t}}}^{2}+\sigma_{b_{w_{t-1}}}^{2}}
$$

Similarly, the glacier-wide surface mass balance $\left(b_{\mathrm{a}}\right)$ for any year $(t)$ is obtained as $B_{a_{t}}=B_{w_{t-1}}+B_{s_{t^{\prime}}}$ with a standard error calculated as:

$$
\sigma_{B_{a_{t}}}=\sqrt{\sigma_{B_{s_{t}}}^{2}+\sigma_{B_{w_{t-1}}}^{2}}
$$

\subsubsection{Years with only winter and annual mass-balance measurements}

In 2006, 2007 and 2008 the network of ablation stakes was only used to support the calculation of annual mass balance (end of summer to the next), which is described in detail by Stumm (2011). In order to incorporate these years into the time series of mass balance, a predictor for annual balance in the form of an annual balance index $(A B I)$ is computed using:

$$
A B I=\rho_{S} S D I_{C K}+M S B I_{C K}
$$

with an associated standard error:

$$
\sigma_{A B I}=\sqrt{\left(\rho_{s} \sigma_{C K}^{S D I}\right)^{2}+\sigma_{C K}^{M S B I^{2}}}
$$

where $\rho_{\mathrm{s}}$ (snow density) is assumed to be equal to $500 \mathrm{~kg}$ $\mathrm{m}^{-3}$. The linear relationships between measurements of annual balance and the values calculated using $A B I$ for each individual year between 2006 and 2008 are shown in Figure 10. Strong and significant correlations are obtained for 2006 and 2007 ( $P$-values $<0.01)$. It is encouraging that mass-balance observations during these 2 years can be determined with a high degree of confidence using $A B I$, which is derived from measurements from all other years, suggesting there is a coherent spatial structure in winter and summer balance. The linear regression for 2008 is not as robust, with a determination coefficient of $R^{2}=45 \%$ ( $P$-value $=$ 0.45). We interpret this as evidence that the proposed approach may also be capable of detecting inconsistencies in the observational record, which are described by Stumm 


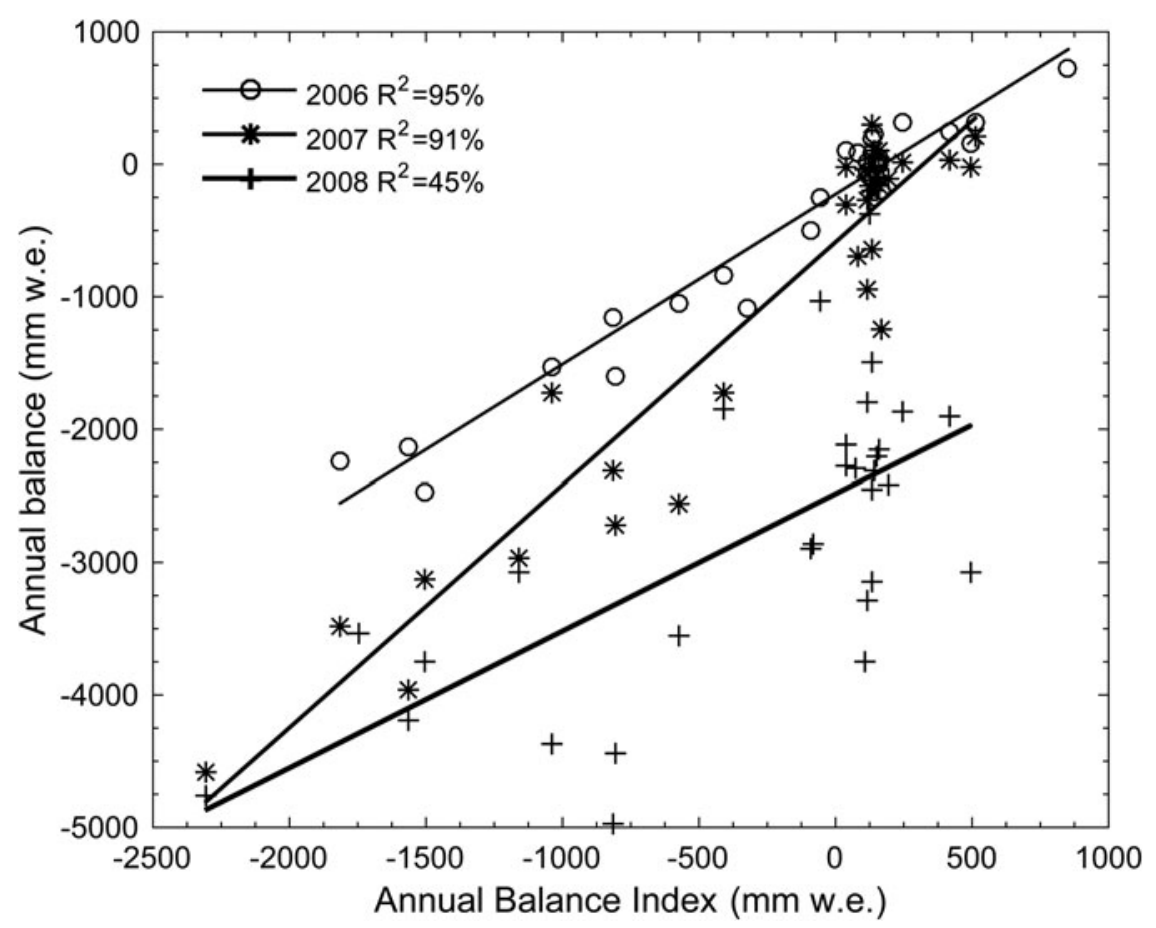

Fig. 10. Annual balance versus $A B I$. Years are offset for clarity.

(2011), but we cannot rule out that secondary processes that are not fully accounted for might be having an effect on mass balance (e.g. Purdie and others, 2015). Importantly, the regression approach based on a predictor of annual balance does benefit from redundancy that helps to mitigate errors associated with the observations, while producing a spatially consistent map of annual balance.

For the 3 years discussed, a map of annual balance $\left(b_{\mathrm{a}}\right)$ for any given year $(t)$ is obtained via linear regression between observations and $A B I$ :

$$
b_{a_{t}}=s_{a_{t}} A B I+O_{a_{t}}
$$

where $s_{a_{t}}$ and $o_{a_{t}}$ are the slope and intercept of the regression (a, annual balance). The standard error in annual balance for any given year $(t) \sigma_{b_{a t}}$ is obtained by:

$$
\sigma_{b_{a_{t}}}=s_{a_{t}} \sigma_{A B l}
$$

Finally, this allows maps of summer balance to be calculated by subtracting winter balance from annual balance, while the associated errors are obtained by Gaussian error propagation. The average and associated standard errors of the glacier-wide values are computed as arithmetic and quadratic means, respectively.

\subsection{ELA and AAR}

Positive values on any given annual balance map define the accumulation area, with the boundary from positive to negative values interpreted as the equilibrium line. The accumulation area ratio for any given year $\left(A A R_{t}\right)$ is computed as the relative share of the accumulation area versus the area of the glacier. The equilibrium line altitude for any given year $\mu_{E L A_{t}}$ is defined as the average elevation along the equilibrium line. Since elevation does not uniquely control annual balance in our approach, the variance of elevation along the equilibrium line is also captured by $\sigma_{E L A_{t}}$. Both $A A R_{t}$ and $\mu_{E L A_{t}}$ are compared with estimates from the EOSS programme (Chinn and others, 2012).

\section{RESULTS AND DISCUSSION}

\subsection{Performance of the co-kriging}

Cross validation of the co-kriging of $S D I$ and $M S B I$ results in mean errors of $0.11 \mathrm{~mm}$ and $4.5 \mathrm{~mm}$ w.e., respectively, which are indicative of negligibly biased models. The RMSE is $441 \mathrm{~mm}$ for SDI and $211 \mathrm{~mm}$ w.e. for MSBI. The largest uncertainty in $S D I$ is on the northern slopes of the accumulation area, with the maximum RMSE equal to $726 \mathrm{~mm}$. This corresponds $\sim 10 \%$ error relative to the average snow depth of $7500 \mathrm{~mm}$ at this location. At the same location, the RMSE for MSBI reaches a maximum of $251 \mathrm{~mm}$ w.e., or $38 \%$ of the average summer balance of $-650 \mathrm{~mm}$ w.e. Although the determination of the co-kriging standard error is rigorous in a geostatistical sense, the quantification of the uncertainty in the upper accumulation area needs to be further scrutinised. The standard error maps are useful as they highlight the need to obtain more data in the upper accumulation area. In the current framework, such samples would have the immediate effect of refining the predictor of snow depth and summer balance, as well as reducing the cokriging variance, which would result in lowering the uncertainties associated in calculating glacier-wide winter, summer and annual balances.

Not only is the $S D I_{C K}$ map useful as a tool to calculate winter balance, it provides detailed information about the spatial variability of snow depth. Although the smoothness of the map cannot resolve the fine spatial structure indicative of the expected heterogeneity in snow distribution (Kerr and others, 2013), locations with accumulation, consistently greater or less than average are identified. In particular, the relatively thin snow cover along the central flowline, despite an increase in elevation, raises the hypothesis that snow is removed either by wind and/or is subject to 
enhanced ablation. Distributed energy and mass-balance modelling (Mölg and others, 2009) or application of a wind field model (e.g. Winstral and Marks, 2002; Dadic and others, 2010) would help to identify the physical processes, beyond those imposed by the hypsometry of the glacier, responsible for the observed spatial variability.

\subsection{Mass balance time series for Brewster Glacier}

The time series of mass balance for Brewster Glacier during the period 2005-15 are shown in Table 2. The glacierwide surface winter $\left(B_{\mathrm{w}}\right)$, summer $\left(B_{\mathrm{s}}\right)$ and annual balances $\left(B_{\mathrm{a}}\right)$ averaged over the observation period are $2484,-2586$ and $-102 \mathrm{~mm}$ w.e., respectively, indicating that the glacier has been losing mass over the period. The variability of $B_{\mathrm{s}}$ is more pronounced than that of $B_{\mathrm{w}}$, with their standard deviations equal to 813 and $372 \mathrm{~mm}$ w.e., respectively. There is no significant correlation between $B_{\mathrm{s}}$ and $B_{\mathrm{w}}$ $\left(R^{2}=0.08, P\right.$-value $\left.=0.39\right)$ and they are statistically independent as determined using the HISC (Gretton and others, 2005) (test statistic $=0.2196<$ test threshold $=0.4918$ ). There is a weak $\left(R^{2}=0.38\right)$ but significant $(P$-value $<0.05)$ correlation between $B_{\mathrm{a}}$ and $B_{\mathrm{w}}$. A much greater coefficient of determination is obtained between $B_{\mathrm{a}}$ and $B_{\mathrm{s}}\left(R^{2}=0.87\right.$, $P$-value $<0.01)$, suggesting that changes in summer balance explain most of the variability in annual balance. This finding is consistent with the findings of Anderson and others (2010), as well as being observed, since the mid20th century, at a large number of other mountain glaciers (Zemp and others, 2015).

\subsection{Comparison of annual ELA and AAR values with EOSS data}

The EOSS altitude, which is used as a surrogate for ELA, has been independently estimated from oblique aerial photography for the entire observational period (Chinn and others, 2005, 2012). Comparing values of ELA and AAR calculated from our spatial modelling of mass balance using glaciological data to those estimated from EOSS observations shows a significant correlation between values derived by the two independent methods ( $P$-values $<0.01$ for ELA and AAR). The spatial modelling approach succeeds in capturing some of the variability in ELA and AAR as determined from the EOSS programme. However, the large ELA discrepancies in 2008 and 2012 and general departure from the ideal 1:1 ratio line, suggest shortcomings in either one or both methods.

Over the 11-year mass-balance period (2005-15), the snowline from the EOSS survey was digitally georeferenced on four occasions, and not always from rectified photographs. For all other years, the snowline altitude is established by applying an interpolation method, which involves arranging all photographs into a sequence based on increasing area of snow cover (descending order of ELAs). 'The photograph being interpolated is then carefully compared and inserted into its appropriate place in the sequence' (Willsman and others, 2015, p. 15). Following this approach, 2008, 2011 and 2012 were assessed as having nearly identical ELAs. Review of these photographs confirms that Brewster Glacier is largely snow free, with only patchy snow cover visible on the north-eastern slopes. This snow versus ice pattern is also largely captured by the spatial modelling approach, with relatively high ELA in 2008 and 2011 but not 2012. Although the glaciological record confirms that the winter balances during the mass-balance years of 2008 and 2011 are similar, as are the summer balances, there are substantial differences between 2011 and 2012 (Table 2). To avoid any uncertainty that may have been introduced from our extrapolation method we examined only collocated stakes and probing locations to assess the differences in mass loss and gain in 2011 and 2012, with mean surface height change at collocated ablation stakes equal to 6845 and $4796 \mathrm{~mm}$, respectively. A comparison of snow depth at the end of the 2010 and 2011 winters, determined from collocated snow probing locations, shows that the snowpack was $28 \%$ thinner in 2011 , with winter balance $20 \%$ lower after taking into account variations in snow density. A comparison of annual balance at the collocated ablation stake and snow probing locations shows that mass loss in 2012 was only $35 \%$ of that observed in 2011 . This confirms that the 2 years were substantially different in terms of annual balance, despite the glacier being assessed as having similar ELAs using the EOSS survey interpolation method.

Removing 2012 from the analysis improves the correlation of ELA derived by the two methods from $R^{2}=0.63$ to $R^{2}=$ 0.82 , with the latter linear regression not significantly

Table 2. Winter, summer and annual mass-balance values for Brewster Glacier. The units for mass-balance values are mm w.e., while mean snow density $\left(\mu_{t-1}^{\rho_{s}}\right)$ for winter balance is $\mathrm{kg} \mathrm{m}^{-3}$

\begin{tabular}{|c|c|c|c|c|c|c|c|c|c|c|}
\hline \multirow[b]{2}{*}{ Year $(t)$} & \multirow[b]{2}{*}{$\mu_{t-1}^{\rho_{s}}$} & \multicolumn{2}{|c|}{ Winter balance } & \multicolumn{2}{|c|}{ Summer balance } & \multicolumn{2}{|c|}{ Annual balance } & \multirow[b]{2}{*}{$A A R_{t}(\%)$} & \multirow[b]{2}{*}{$\mu_{E L A_{t}}$} & \multirow[b]{2}{*}{$\sigma_{E L A_{t}}$} \\
\hline & & $B_{w_{t-1}}$ & $\sigma_{B_{w_{t-1}}}$ & $B_{s_{t}}$ & $\sigma_{B_{s_{t}}}$ & $B_{a_{t}}$ & $\sigma_{B_{a_{t}}}$ & & & \\
\hline 2005 & 496 & 2875 & 205 & -1499 & 137 & 1376 & 247 & 92 & 1810 & 57 \\
\hline 2006 & 506 & 2248 & 164 & -1557 & 327 & 691 & 283 & 60 & 1892 & 47 \\
\hline 2007 & 574 & 3039 & 157 & -2347 & 433 & 692 & 403 & 53 & 1896 & 47 \\
\hline 2008 & 474 & 2392 & 183 & -4090 & 292 & -1698 & 228 & 14 & 2092 & 60 \\
\hline 2009 & 498 & 1975 & 162 & -2677 & 135 & -702 & 211 & 27 & 1977 & 34 \\
\hline 2010 & 500 & 2838 & 144 & -2911 & 193 & -74 & 241 & 38 & 1928 & 29 \\
\hline 2011 & 438 & 2154 & 138 & -3882 & 126 & -1728 & 187 & 2 & 2301 & 14 \\
\hline 2012 & 487 & 1945 & 177 & -2510 & 218 & -565 & 281 & 32 & 1951 & 28 \\
\hline 2013 & 448 & 2684 & 178 & -2483 & 378 & 201 & 418 & 43 & 1902 & 45 \\
\hline 2014 & 516 & 2682 & 231 & -2212 & 293 & 470 & 373 & 49 & 1896 & 43 \\
\hline 2015 & 472 & 2492 & 200 & -2277 & 242 & 215 & 314 & 43 & 1911 & 41 \\
\hline Mean & 492 & 2484 & $178^{\mathrm{a}}$ & -2586 & $270^{a}$ & -102 & $299^{a}$ & & & \\
\hline
\end{tabular}

The values in bold show the mean snow density and mass-balance values.

a Quadratic average. 

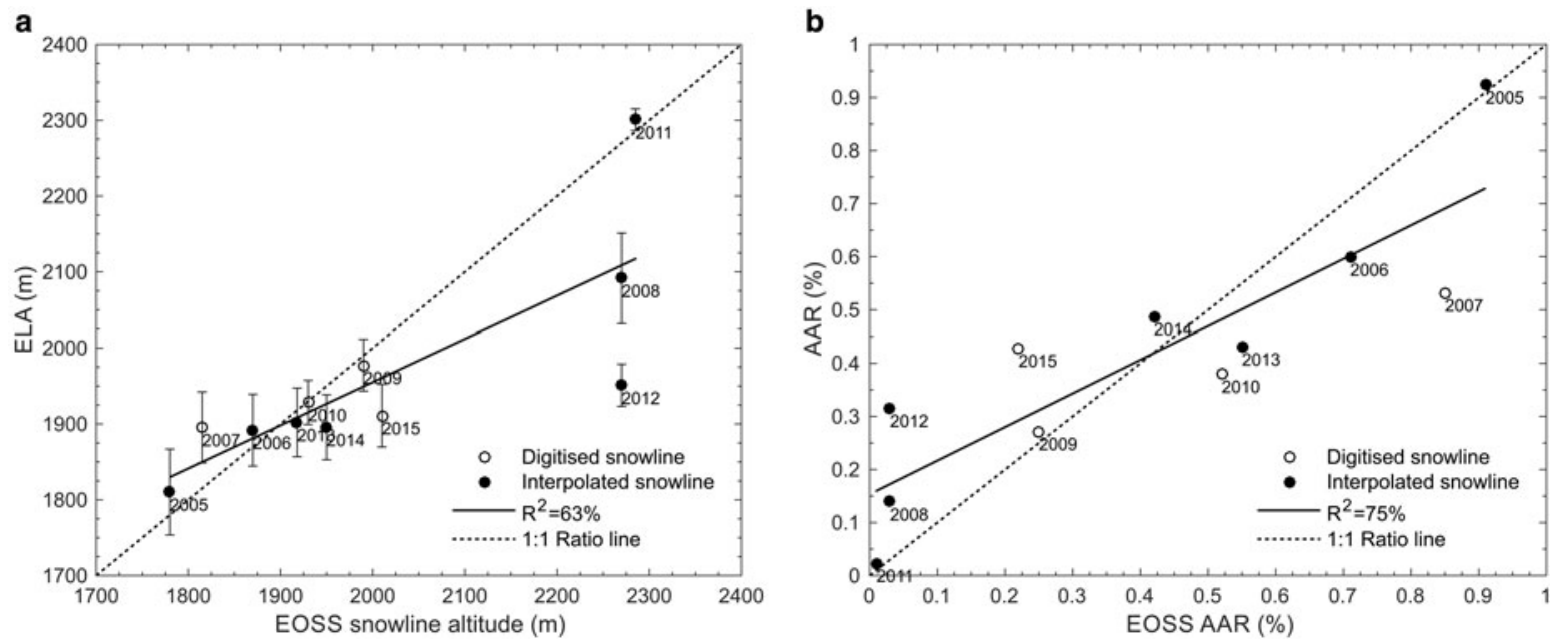

Fig. 11. Comparison between (a) ELA and (b) AAR from the spatial modelling of mass balance and the values determined from the EOSS (Willsman and others, 2015).

different to the 1:1 ratio line at the $95 \%$ confidence level (Fig. 11a). Any uncertainty in the determination of ELA following the two methods also has implications for the calculation of AAR. However, when ELA is $>2000 \mathrm{~m}$ a.s.l., variations in the two estimates only correspond to small variations in AAR because of the hypsometry of the glacier. For this reason, the linear regression between the two differently derived AAR values is more robust $\left(R^{2}=0.75, P\right.$-value $<$ 0.01) than the ELA relationship over the entire period (Fig. 11b), and further improves if 2012 is discarded $\left(R^{2}=\right.$ 0.79 ). This suggests that AAR may be a better primary variable to assess mass balance than ELA.

\subsection{Resolving equilibrium state ELA and AAR}

To determine values of ELA and AAR on Brewster Glacier representative of the observation period, a mass-balance map of the glacier in an equilibrium state $\left(b_{a_{\text {eq }}}\right)$ is defined as:

$$
b_{a_{e q}}=\overline{b_{a_{t}}}-\overline{B_{a_{t}}}
$$

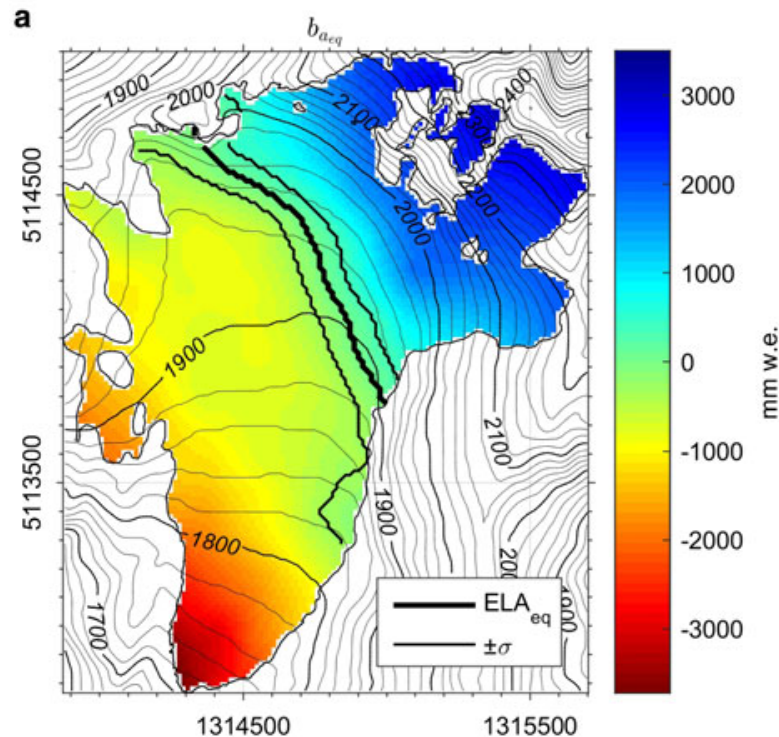

where $\overline{b_{a_{t}}}$ is the spatially averaged map computed from the sequence of annual balance maps and $\overline{B_{a_{t}}}$ the mean of the glacier-wide annual balances. By definition, the glacier in equilibrium $\left(b_{a_{e q}}\right)$ has a glacier-wide mass balance equal to zero (balanced-budget), from which representative equilibrium values of ELA and AAR can be determined using the $b_{a_{e q}}=0$ line (Fig. 12a). The uncertainties in $\mathrm{ELA}_{\text {eq }}$ and $\mathrm{AAR}_{\text {eq }}$ are obtained using the uncertainty associated with $b_{a_{\text {eq }}}$ determined by propagating the mapped standard error of $b_{a_{t}}$ with that of $\overline{B_{a_{t}}}$ (Table 2), which results in $1898 \pm 39 \mathrm{~m}$ a.s.l. $<\mathrm{ELA}_{\mathrm{eq}}=1923 \pm 25 \mathrm{~m}$ a.s.l. $<1938 \pm 28 \mathrm{~m}$ a.s.l. and $0.35<\mathrm{AAR}_{\mathrm{eq}}=0.40<0.47$ (Fig. 12b).

Given the importance of using EOSS as a method to monitor glacier behaviour in the Southern Alps (Chinn and others, 2005, 2012), it is of interest to compare ELA ${ }_{\text {eq }}$ and $A A R_{\text {eq }}$ values to those determined from the EOSS programme. As described by Chinn and others (2012), EOSS elevations are typically reported as departures from the longterm $\mathrm{ELA}_{0}$. The ELA $\mathrm{E}_{0}$ for Brewster Glacier was initially estimated using AAR, assuming the ratio of the accumulation

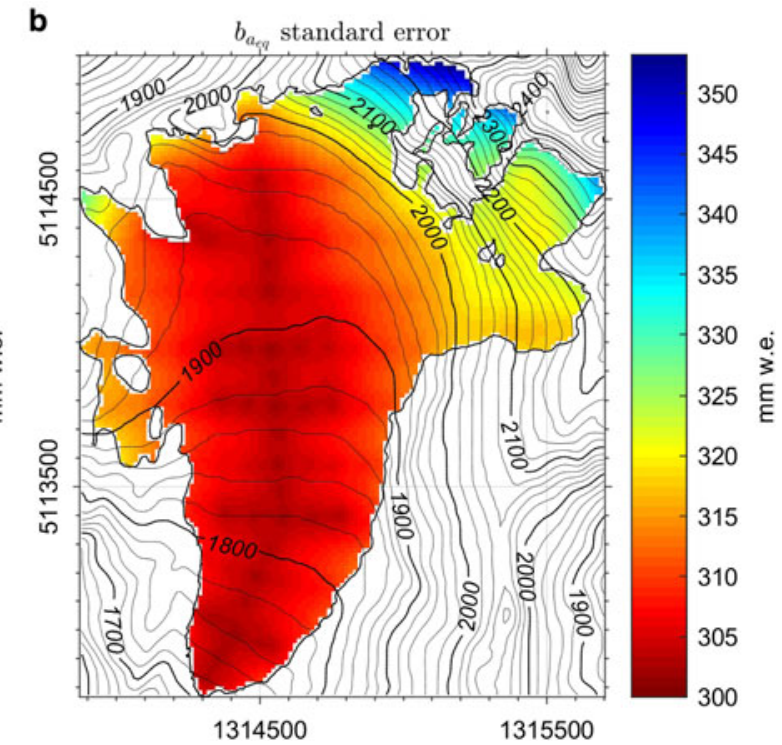

Fig. 12. (a) Mass-balance map of the glacier in an equilibrium state $\left(b_{a_{e q}}\right)$ and (b) associated standard error. 
a

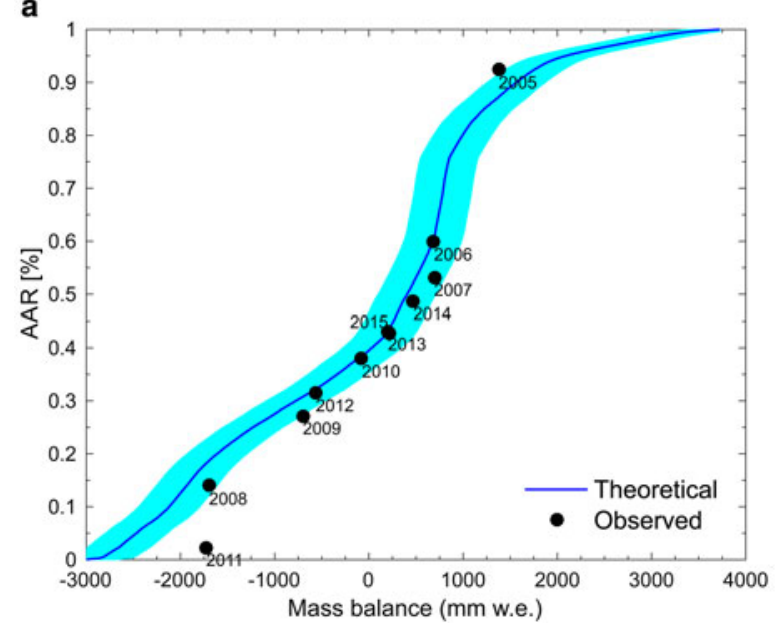

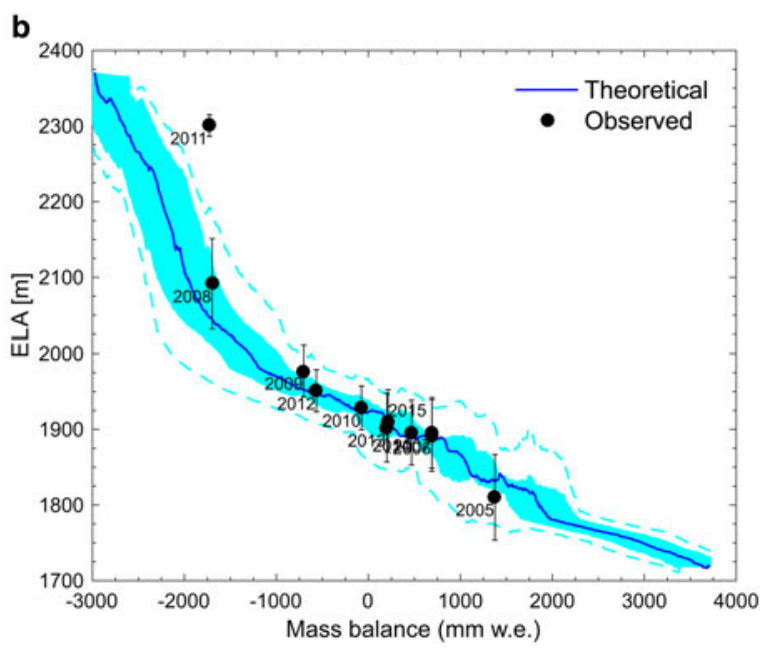

Fig. 13. Relationships between mass balance and (a) AAR and (b) ELA for Brewster Glacier. The solid line is derived using $b_{a_{e q}}$. The envelope corresponds to uncertainties associated with $B_{a_{i}}$. The dots indicate the values derived from the modelling of annual balance for each year, with error bars showing $\sigma_{E L A_{t}}$. The dotted lines in (b) show the expected magnitude of $\sigma_{E L A_{t}}$.

area to the full glacier area was equal to $2: 1$ or 0.66 . As the EOSS programme matured, the initial $\mathrm{ELA}_{0}$ was adjusted by regressing annual departures from $\mathrm{ELA}_{0}$ on Brewster Glacier against the annual mean departure from $\mathrm{ELA}_{0}$ measured across the Southern Alps (ELA Alps). The constant of the regression is used to adjust $\mathrm{ELA}_{0}$ assuming a zero average mass balance for the Southern Alps (Chinn and others, 2012). This adjustment has been applied on two occasions to Brewster Glacier, resulting in $\mathrm{ELA}_{0}$ changing from 1880 to $1905 \mathrm{~m}$ a.s.l. in $1999\left(\mathrm{AAR}_{0}=0.6\right)$ and to $\mathrm{ELA}_{0}=1935 \mathrm{~m}$ a.s.I. $\left(\mathrm{AAR}_{0}=0.5\right)$ in 2003. As noted by Willsman and others (2015, p. 16) estimates of $\mathrm{ELA}_{0}$ are 'dependent on the accuracy of the digitised accumulation and/or ablation areas, glacier area and its area elevation curve'. In other words, the glacier outline and DEM being used control the relationship between $\mathrm{ELA}_{0}$ and $\mathrm{AAR}_{0}$. For example, applying the $1: 1$ ratio $(A A R=0.5)$ using the dataset in this study results in $\mathrm{ELA}_{0}=1918 \mathrm{~m}$ a.s.l., $17 \mathrm{~m}$ below the ELA $\mathrm{E}_{0}$ reported for EOSS computations. The calculation of AAR is also subject to variability depending on the approach used to determine its value. Two-dimensional mapping of the equilibrium line in $b_{e q}$ yields $\mathrm{AAR}_{\mathrm{eq}}=0.4$ for $\mathrm{ELA}_{\mathrm{eq}}=1923 \mathrm{~m}$ a.s.l., while a 1-D approach using an area elevation curve yields an AAR of 0.46, which is closer to the EOSS-determined $\mathrm{AAR}_{0}$. Clearly, these examples demonstrate the obvious, which is the calculation of ELA and/or AAR is sensitive to the method chosen to do it (e.g. Braithwaite, 2015).

\subsection{Theoretical relationship between ELA, AAR and mass balance}

The relationship between ELA, AAR and mass balance has been central to revealing linkages between glacier behaviour and climate, and has been used effectively in efforts to monitor changes in mass balance using remote-sensing methods. To determine mass balance from ELA and/or AAR using remote sensing it is important that the effects of glacier hypsometry are taken into account. The area-altitude distribution of a glacier can distort the relationship between mass balance and ELA or AAR, and may result in the commonly-used linear relationship being valid only within certain elevation ranges (Khalsa and others, 2004). Our glacier in equilibrium $\left(b_{a_{e q}}\right)$ map (Fig. 12) provides us with an opportunity to explore and characterize the shape of such relations for Brewster Glacier. Figure 13 shows that despite inflexion points the AAR relationship is close to linear over the annual mass-balance range $(-3000$ to $2000 \mathrm{~mm}$ w.e. When AAR exceeds 0.95 (glacier nearly fully snow covered at the end of the ablation season), it is clear that the linear relationship would underestimate the very positive balance. The relationship between mass balance and ELA is also linear until it reaches an altitude of $\sim 2050 \mathrm{~m}$ a.s.l. At and above this altitude, ELA would be located on the upper, steep slopes and if it were to continue to increase in elevation the change in mass balance would be small. All data points fit the theoretical shapes well, except in 2011 when the mass balance is similar to 2008 but ELA is much higher. It is possible that in this very negative year, the regime of ablation departed from its typical shape predicted by $M S B I_{C K}$ using linear regression. This is supported by the relatively low correlation between stake ablation and $M S B I_{C K}$ for this year $\left(R^{2}=0.62\right)$. Nonetheless, the relationships shown in Figure 13 are important for our understanding of the behaviour of Brewster Glacier and are likely to be useful in reconstructing mass balance using remotesensing methods. They also shed new light on whether it is always appropriate to assume linearity for such relationships.

\subsection{Mass-balance gradient}

The mass-balance gradient, defined as the rate of change of mass balance with altitude, is an important parameter in determining mass balance using remote-sensing methods (e.g. Rabatel and others, 2005; Chinn and others, 2012). Extrapolation of a known mass-balance gradient to neighbouring regions characterised by similar climatic conditions enables mass balance to be determined in areas where no glaciological field data are available. This approach is used by Chinn and others (2012) to estimate ice volume changes in the Southern Alps using the EOSS record, with massbalance gradients determined from glaciological measurements on three glaciers, including Brewster Glacier. Massbalance gradients in the ablation area of glaciers in the 


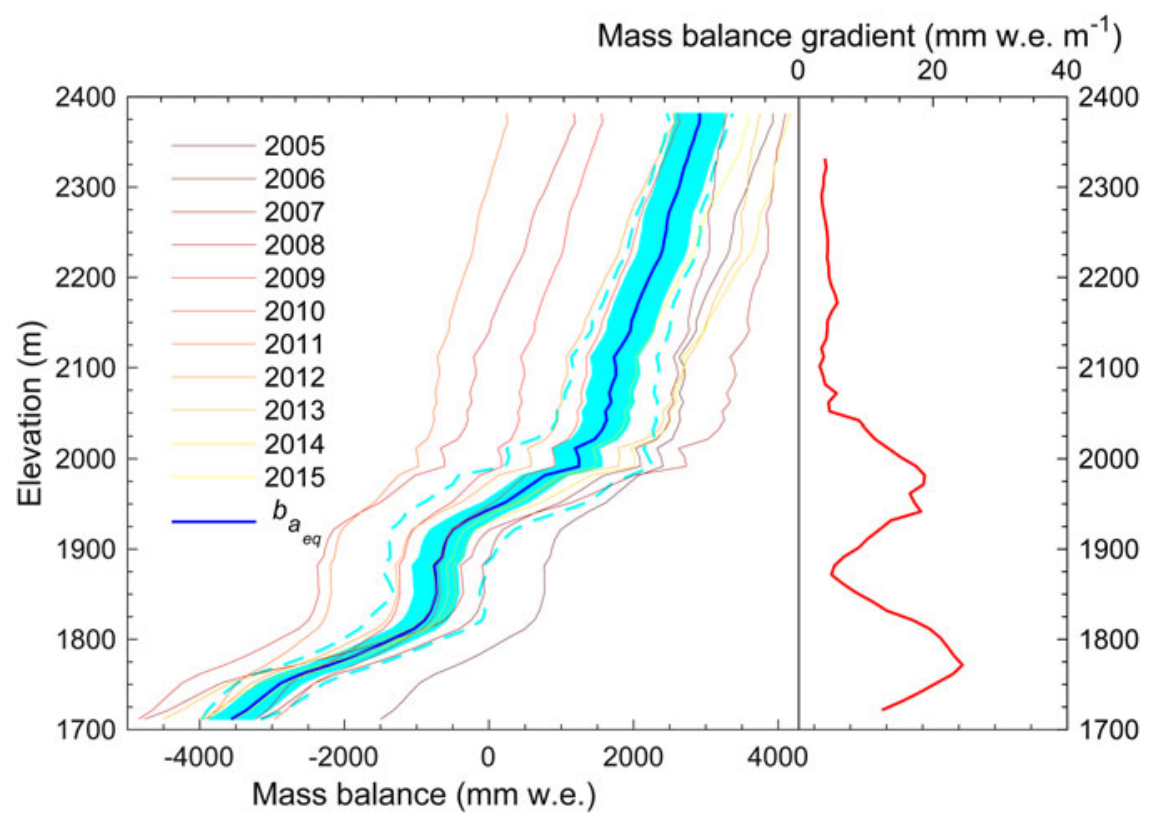

Fig. 14. Altitudinal mass balance and derived gradient of Brewster Glacier. The envelope corresponds to uncertainties associated with $B_{a_{t}}$. The dotted lines depict the spread of $b_{a_{e q}}$ along altitudinal contours.

Southern Alps are assumed to be twice those of the accumulation area by Chinn and others (2012), while higher values are assigned to the 'wet' western glaciers, and lower values to the 'dry' eastern glaciers. Following this approach, mass gradients west (east) of the Main Divide of the Southern

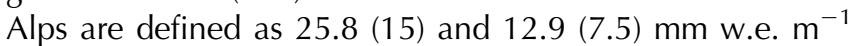
for the ablation and accumulation areas, respectively. For Brewster Glacier, the average mass-balance gradients are reported as 19.9 and $6.8 \mathrm{~mm}$ w.e. $\mathrm{m}^{-1}$ for the ablation and accumulation areas, respectively.

In this context, it is worth examining the typical altitudinal mass-balance gradient from $b_{a_{\mathrm{eq}}}$. Figure 14 shows the nature of the relationship between mass balance and elevation, as well as the derived gradient. Although the values are in general agreement with the estimates derived by Stumm (2011), Figure 14 reveals some additional information. The mass-balance gradient peaks twice, namely in the lower ablation zone and around ELA $\mathrm{eq}_{\mathrm{eq}}$ with the gradient approaching or exceeding $25 \mathrm{~mm}$ w.e. $\mathrm{m}^{-1}$. The elevation band between 1840 and $1920 \mathrm{~m}$ a.s.l. has a lower gradient, which is similar to the gradient of $5 \mathrm{~mm}$ w.e. $\mathrm{m}^{-1}$ above $2000 \mathrm{~m}$ a.s.I. On average, the altitudinal gradients of $b_{a_{e q}}$ are equal to 14.5 and $7.4 \mathrm{~mm}$ w.e. $\mathrm{m}^{-1}$ in the ablation and accumulation zones, respectively (i.e. upward and downward of $\mathrm{ELA}_{\mathrm{eq}}$, respectively). These depart slightly from the values reported by Chinn and others (2012) for Brewster Glacier but differ from those expected for a glacier that is located west of the Main Divide. In fact, they are quite similar to the average mass-balance gradients estimated for Tasman Glacier and the mean values used for the 'dry' eastern index glaciers. This raises the question as to whether it is appropriate to simply partition glaciers into two mass-balance gradient categories based on whether they are west or east of the Main Divide (e.g. Chinn and others, 2012). There is also considerable variability in the average annual mass-balance gradient on Brewster Glacier (Table 3), as well as at the ELA and in the ablation/accumulation zones. The largest variation in the mass-balance gradient is in the ablation zone, which is consistent with the finding that summer balance tends to have the largest influence on annual mass balance. Beyond documenting this record, the observed variability is likely to be useful in determining uncertainties in deriving mass balance using methods such as proposed by Rabatel and others (2005).

\subsection{Limitations of the method}

Our proposed interpolation scheme makes the assumption that indices of snow depth and ablation do not change over time. This is justified in this study due to the relatively short period of analysis, but the assumption would need to be scrutinised over a longer time period. For example, changes in the surface elevation and topography of Brewster Glacier over time or a shift in climate are likely to lead to changes in the regimes of accumulation and/or ablation. In some respects, our approach is similar to that proposed by Lliboutry (1974), who developed a linear model

Table 3. Mass-balance gradients for each year

\begin{tabular}{lrrrr}
\hline & \multicolumn{4}{c}{ Mass-balance gradient mm w.e. $\mathrm{m}^{-1}$} \\
\cline { 2 - 5 } Year & Average & Ablation & Accumulation & At ELA \\
\hline 2005 & 8.1 & 15.8 & 6.8 & 15.4 \\
2006 & 9.8 & 16.5 & 7.0 & 9.7 \\
2007 & 13.5 & 23.6 & 9.4 & 13.8 \\
2008 & 9.0 & 11.9 & 4.7 & 3.2 \\
2009 & 7.1 & 10.6 & 4.6 & 12.6 \\
2010 & 8.4 & 11.6 & 6.7 & 11.7 \\
2011 & 6.2 & 6.4 & 3.5 & 3.4 \\
2012 & 9.7 & 13.7 & 7.4 & 16.3 \\
2013 & 12.6 & 19.4 & 9.6 & 12.3 \\
2014 & 12.4 & 19.1 & 9.7 & 10.8 \\
2015 & 10.7 & 15.4 & 8.6 & 10.7 \\
Mean & $\mathbf{9 . 8}$ & $\mathbf{1 4 . 9}$ & $\mathbf{7 . 1}$ & $\mathbf{1 0 . 9}$ \\
$\boldsymbol{\sigma}$ & $\mathbf{2 . 3}$ & $\mathbf{4 . 8}$ & $\mathbf{2 . 1}$ & $\mathbf{4 . 2}$ \\
\end{tabular}

The values in bold show the mean and standard deviation of the massbalance gradients. 
to calculate mass balance using site (spatial term) and year (temporal term) as independent variables. By using all available data over 16 consecutive years (1956-72) from the ablation area of Glacier de Saint-Sorlin (French Alps) to regress both terms, Lliboutry (1974) mitigated problems associated with observational error from any particular year. The multi-variate statistical method has also been used in conjunction with geodetic measurements to enable estimates of mass balance (Thibert and Vincent, 2009). Eckert and others (2011) further refined the method by relaxing the assumption of stationarity, enabling temporal trends to be characterised in a mass-balance series obtained from Glacier de Sarennes (French Alps). However, this approach does not explicitly account for spatial variability in the mass-balance record. By focusing on both the spatial and temporal structure of mass-balance variability using a geostatistical method, while utilising the entire dataset available, our method to some extent fills the gap between the purely statistical approaches of Lliboutry (1974) and Eckert and others (2011) and the more traditional semi-empirical methods of interpolating (extrapolating) glaciological observations using altitude. We do this by using our indices to represent to some degree the spatial term proposed by Lliboutry (1974), while the temporal term is captured by the slope and offset of the linear regression between our glaciological measurements and the indices. Further observations spread over a longer timeframe will enable the indices to be refined spatially, as well as to reduce their standard error under the assumption of stationarity. In the future, new indices could be considered for different timeframes to explore temporal variations in the spatial structure of accumulation and ablation. Improvements to our massbalance estimates could also be achieved through validation using geodetic mass-balance estimates (e.g. Zemp and others, 2013) and/or homogenization of the record using a distributed energy-balance model (e.g. Huss and others, 2009). The latter would overcome the deficiencies associated with mass balance being evaluated between the dates of successive field surveys, rather than an evaluation between fixed dates (e.g. a hydrological year).

\section{CONCLUSION}

We have reported on the glaciological measurements used to reconstruct mass balance on Brewster Glacier. The efforts to gather glaciological observations on Brewster Glacier have been considerable, with a large number of people contributing in different ways since 2004. Despite the logistical challenges, it is the longest in situ record of a glacier's mass change ever obtained in the Southern Alps and as a result, has become an important benchmark for a range of glaciological and meteorological studies. To reduce spatial and temporal artefacts introduced by changes to the measurement regime as the mass-balance programme evolved, we re-analysed all the observational data and developed a new geostatistical method to calculate mass balance. We have shown that the spatial structure of winter and summer balance over Brewster Glacier for any individual massbalance year contains sufficient similarity to other years to enable indices to be determined for both. The newly derived indices are more powerful than elevation in revealing the spatial structure of winter and summer balance. Changes in winter and summer mass balance were obtained directly by calibrating the indices with data points available for any given year, which helped distribute errors associated with potential artefacts introduced from outliers from any individual mass-balance year. The method also enabled a predictor for annual balance to be resolved, which was used specifically for years where values of summer balance were not available.

The average glacier-wide surface winter, summer and annual mass balances for the period 2005-15 were 2484, -2586 and $-102 \mathrm{~mm}$ w.e., respectively. The variability in summer balance was greater than in the winter balance, with the strong relationship between summer and annual balance $\left(R^{2}=0.87, P\right.$-value $\left.<0.01\right)$ suggesting ablation processes exert the largest control on annual balance. On the whole, there is good agreement between our ELA and AAR values and those derived from the EOSS programme (Chinn and others, 2005, 2012), though discrepancies in some years could not be fully accounted for. A mass-balance map of Brewster Glacier in an equilibrium state, which by definition has a glacier-wide mass balance equal to zero, was used to calculate values of ELA $(1923 \pm 25 \mathrm{~m}$ a.s.l. $)$ and AAR (0.40) representative of the observational period. The relationships between mass balance and ELA/AAR were explored, demonstrating they are mostly linear, which provides a foundation for reconstructing mass balance using remote-sensing methods. On average, the massbalance gradients were found to be equal to 14.5 and 7.4 $\mathrm{mm}$ w.e. $\mathrm{m}^{-1}$ in the ablation and accumulation zones, respectively, but there is considerable variability from year to year, especially in the ablation zone. We also observed variability in the mass-balance gradients between different elevation bands, clearly demonstrating that care must be taken when prescribing fixed mass-balance gradients to estimate glacier volume changes in the Southern Alps.

The geostatistical approach used in this research provides a robust and transparent method to assess the spatial and temporal variability of mass balance, which should allow the data from Brewster Glacier to be easily integrated into global glacier monitoring databases. This mass-balance record provides a baseline for future research, and has already been useful in efforts to build new linkages between large-scale atmospheric circulation and glacier behaviour in the Southern Alps, as well as to reconstruct glacier behaviour over the EOSS period (1977-present) using a remote-sensing method (e.g. Sirguey and others, 2016). Because the method takes advantage of the entire glaciological record to help refine the predictors of mass balance (defined as indices), it will continue to be improved over time, which will allow issues of non-stationarity to also be assessed. In the short term, observational data from the upper accumulation area will be gathered to help reduce uncertainties in the calculation of mass balance. A geodetic survey of mass balance and/or homogenization of the observed mass-balance record using a distributed energybalance model are the next logical steps to further scrutinise the newly constructed record.

\section{ACKNOWLEDGEMENTS}

N.J.C. received support from the Alexander von Humboldt Foundation to complete this research. The research was funded in-part by the National Institute of Water and Atmospheric Research (NIWA) project 'Climate Present and Past'. B.A. and A.M. contributions were also supported by the NIWA Regional Climate Modelling programme. This 
research was conducted under the Department of Conservation concession OT-32299-OTH. Chris Garden provided field and technical support and helped to review the probe and ablation stake locations in 2014.

\section{CONTRIBUTION STATEMENT}

N.J.C. and B.A. designed the research and led the massbalance programme on Brewster Glacier. N.J.C. led the coordination and writing, B.A. contributed to the data analysis and writing, P.S. developed the geostatistical method, produced the figures and contributed significantly to the writing, D.S. oversaw the mass-balance measurements between 2005 and 2007, and A.M., J.P.C., R.D., H.J.H., S.J.F. and A.L. provided field and/or logistical support to the mass-balance programme. All authors contributed to the final manuscript.

\section{REFERENCES}

Anderson B and 6 others (2010) Climate sensitivity of a high-precipitation glacier in New Zealand. J. Glaciol., 56(195), 114-128 (doi: 10.3189/002214310791190929)

Braithwaite RJ (2015) From Doktor Kurowski's Schneegrenze to our modern glacier equilibrium line altitude (ELA). Cryosphere, 9, 2135-2148 (doi: 10.5194/tc-9-2135-2015)

Chinn TJ, Heydenrych C and Salinger MJ (2005) Use of ELA as a practical method of monitoring glacier response to climate in New Zealand's Southern Alps. J. Glaciol., 51(172), 85-95 (doi: http://dx.doi.org/10.3189/172756505781829593)

Chinn T, Fitzharris BB, Willsman A and Salinger MJ (2012) Annual ice volume changes 1976-2008 for the New Zealand Southern Alps. Glob. Planet. Change, 92-93, 105-118 (doi: 10.1016/j. gloplacha.2012.04.002)

Clare GR, Fitzharris BB, Chinn TJH and Salinger MJ (2002) Interannual variation in end-of-summer snowlines of the Southern Alps of New Zealand, and relationships with Southern Hemisphere atmospheric and sea surface temperature patterns. Int. J. Climatol., 22, 107-120 (doi: 10.1002/joc.722)

Cogley JG and 10 others (2011) Glossary of Glacier Mass Balance and Related Terms, IHP-VII Technical Documents in Hydrology No. 86, IACS Contribution No. 2, UNESCO-IHP, Paris

Conway JP and Cullen NJ (2013) Constraining turbulent heat flux parameterization over a temperate maritime glacier in New Zealand. Ann. Glaciol., 54(63), 41-51 (doi: 10.3189/2012AoG63A604)

Conway JP and Cullen NJ (2016) Cloud effects on the surface energy and mass balance of Brewster Glacier, New Zealand. Cryosphere, 10, 313-328 (doi: 10.5194/tc-10-313-2016)

Conway JP, Cullen NJ, Spronken-Smith RA and Fitzharris SJ (2015) All-sky radiation over a glacier surface in the Southern Alps of New Zealand: characterizing cloud effects on incoming shortwave, longwave and net radiation. Int. J. Climatol., 35, 699713 (doi: 10.1002/joc.4014)

Columbus J, Sirguey P and Tenzer R (2011) A free, fully assessed 15m DEM for New Zealand. Surv. Quart., 66, 16-19

Cullen NJ and Conway JP (2015) A 22 month record of surface meteorology and energy balance from the ablation zone of Brewster Glacier, New Zealand. J. Glaciol., 61(229), 931-946 (doi: 10.3189/2015JoG15J004)

Dadic R, Mott R, Lehning M and Burlando P (2010) Wind influence on snow depth distribution and accumulation over glaciers. J. Geophys. Res., 115, F01012 (doi: 10.1029/2009JF001261)

Eckert N, Baya H, Thibert E and Vincent C (2011) Extracting the temporal signal from a winter and summer mass-balance series: application to a six-decade record at Glacier de Sarennes, French Alps. J. Glaciol., 57(201), 134-150 (doi: 10.3189/ 002214311795306673)

Elsberg DH, Harrison WD, Echelmeyer KA and Krimmel RM (2001) Quantifying the effects of climate and surface change on glacier mass balance. J. Glaciol., 47(159), 649-658 (doi: 10.3189/ 172756501781831783)

Fitzharris BB, Hay JE and Jones PD (1992) Behaviour of New Zealand glaciers and atmospheric circulation changes over the past 130 years. Holocene, 2, 97-106 (doi: 10.1177/ 095968369200200201)

Fitzharris BB, Chinn TJ and Lamont GN (1997) Glacier balance fluctuations and atmospheric patterns over the Southern Alps, New Zealand. Int. J. Climatol., 17, 1-19 (doi: 10.1002/(SICI)10970088(19970615)17:7<745::AID-JOC160>3.0.CO;2-Y)

Fountain AG and Vecchia A (1999) How many stakes are required to measure mass balance of a glacier? Geogr. Ann. A., 81, 563-573 (doi: 10.1111/1468-0459.00084)

George LA (2005) Mass balance and climate interactions at Brewster Glacier, 2004/5. (thesis, Masters of Science, University of Otago)

Gillett S and Cullen NJ (2011) Atmospheric controls on summer ablation over Brewster Glacier, New Zealand. Int. J. Climatol., 31(13), 2033-2048 (doi: 10.1002/joc.2216)

Goovaerts P (1998) Geostatistical tools for characterizing the spatial variability of microbiological and physico-chemical soil properties. Biol. Fertil. Soils, 27, 315-334 (doi: 10.1007/s003740050439)

Gretton A, Bousquet O, Smola A and Schцlkopf B (2005) Measuring statistical dependence with Hilbert-Schmidt Norms. In Jain S, Simon HU and Tomita E eds. Algorithmic Learning Theory, Springer, Berlin, Heidelberg, pp. 63-77

Huss M, Bauder A and Funk M (2009) Homogenization of longterm mass-balance time series. Ann. Glaciol., 50(50), 198-206 (doi: 10.3189/172756409787769627)

Kerr T, Clark M, Hendrikx J and Anderson B (2013) Snow distribution in a steep mid-latitude alpine catchment. Adv. Water Resour., 55, 17-24 (doi: 10.1016/j.advwatres.2012.12.010)

Khalsa SJS, Dyurgerov MB, Khromova T, Raup BH and Barry RG (2004) Space-based mapping of glacier changes using ASTER and GIS tools. IEEE Trans. Geosci. Remote Sens., 42, 21772183 (doi: 10.1109/TGRS.2004.834636)

Lliboutry L (1974) Multivariate statistical analysis of glacier annual balances. J. Glaciol., 13, 371-392

Mölg T, Cullen NJ, Hardy DR, Winkler M and Kaser G (2009) Quantifying climate change in the tropical mid troposphere over East Africa from glacier shrinkage on Kilimanjaro. J. Climate, 22, 4162-4181 (doi: 10.1175/2009JCLI2954.1)

Purdie $\mathrm{H}$ and 6 others (2015) The impact of extreme summer melt on net accumulation of an avalanche fed glacier, as determined by ground-penetrating radar. Geogr. Ann. A., 97, 779-791 (doi: 10.1111/geoa.12117)

Rabatel A, Dedieu J-P and Vincent C (2005) Using remote-sensing data to determine equilibrium-line altitude and mass-balance time series: validation on three French glaciers. J. Glaciol., 51, 539-546 (doi: 10.3189/172756505781829106)

Rossi RE, Mulla DJ, Journel AG and Franz EH (1992) Geostatistical tools for modeling and interpreting ecological spatial dependence. Ecol. Monogr., 62(2), 277-314 (doi: 10.2307/2937096)

Sirguey P and 5 others (2016) Reconstructing the mass balance of Brewster Glacier, New Zealand, using MODIS-derived glacierwide albedo. Cryosphere, 10, 2465-2484 (doi: 10.5194/tc-102465-2016)

Stumm D (2011) The mass balance of selected glaciers of the Southern Alps in New Zealand. (thesis, Doctor of Philosophy, University of Otago). Retrieved from http://hdl.handle.net/ 10523/1672

Thibert E and Vincent C (2009) Best possible estimation of mass balance combining glaciological and geodetic methods. Ann. Glaciol., 50, 112-118 (doi: http://dx.doi.org/10.3189/ 172756409787769546)

Wackernagel H (2003) Multivariate Geostatistics, An Introduction with Applications. Springer-Verlag, Berlin, Heidelberg

Willis I, Lawson W, Owens I, Jacobel B and Autridge J (2009) Subglacial drainage system structure and morphology of Brewster Glacier, New Zealand. Hydrol. Process., 23, 384-396 (doi: 10.1002/hyp.7146) 
Willsman AP, Chinn TJ and Lorrey A (2015) New Zealand Glacier Monitoring: End of summer snowline survey 2014. Prepared for New Zealand Ministry of Business, Innovation and Employment by National Institute of Water and Atmospheric Research (NIWA) Ltd: Christchurch. NIWA Client Report No: CHC2015-044

Winstral A and Marks D (2002) Simulating wind fields and snow redistribution using terrain-based parameters to model snow accumulation and melt over a semi-arid mountain catchment. Hydrol. Process., 16, 3585-3603 (doi: 10.1002/hyp.1238)
Zemp M, Hoelzle M and Haeberli W (2009) Six decades of glacier mass-balance observations: a review of the worldwide monitoring network. Ann. Glaciol., 50(50), 101-111 (doi: 10.3189/ 172756409787769591)

Zemp M and 16 others (2013) Reanalysing glacier mass balance measurement series. Cryosphere, 7, 1227-1245 (doi: 10.5194/ tc-7-1227-2013)

Zemp M and 33 others (2015) Historically unprecedented global glacier decline in the early 21 st century. J. Glaciol., 61(228), 745-762 (doi: 10.3189/2015JoG15J017)

MS received 2 June 2016 and accepted in revised form 2 November 2016; first published online 1 December 2016 